\title{
Identifying people in poverty: A multidimensional deprivation measure for the EU
}

\author{
Selçuk Bedük \\ Institute of Social and Economic Research \\ University of Essex \\ s.beduk@essex.ac.uk
}




\section{Abstract}

In this article, I propose a multidimensional deprivation measure of poverty for the EU. The paper stands on the claim that a deprivation measure can be adequate, both conceptually and empirically, to capture poverty in the EU defined in Townsendian terms. Yet existing deprivation scales have three conceptual problems such as data-driven specification, neglected dimensionality and missing dimensions, and four data problems such as limited extent, cross-cultural equivalization, behavioral choices and reporting error. To address conceptual problems, I offer a concept-led methodology for constructing a multidimensional measure. To address data problems, I apply a post-hoc adjustment strategy using dual criteria of income poverty and financial strain. The proposed measure has four dimensions, namely needs for basic goods, health, education, leisure and social relationships, where each dimension is evaluated separately with relevant scales. When compared to the formal EU 2020 poverty target measure, the proposed measure is more likely to capture people with needs and lower resources as well as those in less affluent countries than those in more affluent countries. The (adjusted) proposed measure can be used as a stand-alone indicator to identify a target population for policy; or the unadjusted proposed measure can be combined with an income poverty measure to identify a worst-off group within that target population. 


\section{Introduction}

Deprivation scales are of greater interest in European poverty research. In many EU countries, deprivation scales are employed as part of formal poverty measures. EU 2020 poverty target measure, UK's child poverty measure and Ireland's official poverty measure all include deprivation scales yet as either complementary or supplementary to traditional income poverty indicators. ${ }^{1}$ For example, according to the EU 2020 poverty target measure, people in poverty are defined as those who experience income poverty or material deprivation. ${ }^{2}$ Combining income and deprivation measures, it is argued, help better identify the scale of the problem to be addressed by anti-poverty policies in EU member states (Nolan and Whelan, 2011).

Various issues can however be raised about this practice of using deprivation measures alongside income poverty measures. First, conceptually, income and deprivation measures are not supplementary or complementary but alternatives to each other (if the aim is to measure poverty defined in Townsendian terms); hence, in theory, an income or a deprivation measure alone can be adequate to

1 Different uses of deprivation measures is arisen due to different interpretations of Townsendian definition of poverty (Berthoud \& Bryan, 2011), the empirical finding of a large mismatch between low income and material deprivation (see Nolan and Whelan, 2011 for a review), the disagreements about how to go about this mismatch empirically (Hick, 2014), and various practical and political considerations related to measuring poverty in a cross-national context (Copeland and Daly, 2012; Maître et al., 2013).

2 Another indicator used in the EU2020 poverty target is low work intensity, which however is argued to conflate the overall measure and provide little extra information (Maitre et al. 2013). 
identify poverty (defined in Towsendian terms) (see also Hick, 2014). ${ }^{3}$ Secondly, both income and deprivation measures suffer from certain validity problems (and mainly similar problems) and combining two imperfect, conceptually different indicators would not necessarily result in one accurate measure. Thirdly, Hick (2014) shows that, despite their current limited form, it is the deprivation and not the income measure that is particularly useful in identifying the people with a pronounced risk of multiple deprivation in the UK. However, Hick argues, the considerably non-ideal nature of existing deprivation measures still limits their ability to distinguish between poverty and non-poverty, and so "advancing the measurement of material deprivation beyond its present, relatively rudimentary state represents an important priority for poverty research (Hick, 2014: 1101)".

Recent proposals by Whelan \& Maître (2012) and Guio et al. (2016) improve existing deprivation scales using an extended set of items collected at the EUSILC survey's material deprivation module. These measures are usually constructed in a summary format where a unidimensional scale based on a few

${ }^{3}$ Relative deprivation theory defines a process in which lack of resources results in exclusion from ordinary living patterns. Different interpretations are made on which part of this definition represents the essence of poverty (Berthoud and Bryan, 2011). While Townsend considers poverty primarily as a lack of resources and exclusion from ordinary living as the consequences of it, others consider poverty as exclusion from ordinary living and the cause being the lack of resources. Regardless of the view taken, income (as a proxy of lack of resources) and deprivation (as a proxy of exclusion from ordinary living patterns) represent alternative measures of the same phenomenon, and both can be a direct or an indirect measure of poverty depending on the view taken. For example, if poverty is defined as exclusion from ordinary living caused by lack of resources, a deprivation measure including enforced criterion can be used a direct measure of poverty; or an income measure which adequately considers non-cash economic resources, saving and debt as well as varying needs due to individual and household characteristics can also be employed as an indirect measure of poverty. 
key deprivation indicators are considered adequate for identifying poverty and reflecting the variance across countries (see e.g. Guio et al. 2017). However, recent empirical evidence has shown that these unidimensional measures might be suffering from significant measurement error i.e. missing certain risk groups or not adequately reflecting socio-economic differentiation within EU countries due to certain conceptual problems such as data-driven specification, neglect of multidimensionality and missing dimensions (Bedük, 2017; 2018a, b). In addition to these conceptual problems, there are also data problems related to the limited extent, the subjectivity and the use of deprivation data in a cross-national setting (see Guio et al. 2017). All these conceptual and data problems are directly consequential for measurement, therefore might result in missing people in poverty (Type II error) or wrongly identifying people in poverty (Type I error).

Developing on the critiques of Bedük (2017; 2018a, b), and Hick (2014), the main objective of this paper is to propose a deprivation measure of poverty for the EU that improves on the problems of existing measures and can empirically perform better in identifying the people in poverty compared to its existing counterparts. Such a measure proves to be a comprehensive, multidimensional measure with a concept-led design reflecting poverty defined in Townsend's relative deprivation framework.

In this context, next section summarizes existing measures and their problems as well as the proposal of the paper on how to solve these problems. The following sections i) elaborate the meaning of poverty within relative deprivation framework (i.e. identify dimensions and conceptual structure) to guide the design of the 
measure; ii) operationalize the explored design with available data; iii) apply a dual adjustment strategy to mitigate the error caused by data problems; and iv) examine the validity of the proposed measure against the EU 2020 poverty target on its ability to capture those with needs and lower resources using a multinomial logistic model. The analysis is held for 25 EU countries using EU-SILC 2009.

\section{Identifying people in poverty - existing measures, their problems and proposals for mitigating possible measurement error}

In European poverty research, poverty is generally defined within the relative deprivation framework of Townsend (1979). In this framework, individuals are in poverty when "their resources are so seriously below those commanded by the average individual or family that they are excluded from ordinary living patterns, customs and activities". This definition makes a clear link between command over resources and conditions of life, and defines a process in which a lack of (economic) resources causes an inability to participate in society.

One way to assess such poverty is using income measures which aim to assess the adequacy of economic resources for social participation. In such measures, household disposable income (usually equivalized for household size and composition) is used as a proxy for resources, and a poverty line is set to represent the level below which resources are considered inadequate for participating in society. However, income as we measure does not include the value of publicly provided services, in-kind benefits, home production, saving and borrowing, past investments in durables, and house ownership and assets which 
are important factors affecting command over resources (Nolan and Whelan, 2007). Moreover, adequacy of resources depends not only on resources but also on geographical price variation and on individual and household needs which are not accounted in the existing forms of these measures (Ravallion, 1996). For example, varying needs for health care, child care, social care, education and work (e.g. transportation) are accounted neither in disposable income nor in poverty line estimates. As a result, it is questionable that commonly used income poverty lines such as $60 \%$ of median income represent a level of exclusion from ordinary living patterns especially when applied in a cross-national context (Goedemé and Rottiers, 2011; Lelkes and Gasior, 2018). ${ }^{4}$ For example, a recent study using reference budgets shows that, in some less affluent EU countries, some of those who are not identified as in poverty by a relative income poverty measure $(60 \%$ of median) still cannot afford to meet their needs for food and housing (Goedeme et al., 2017). Another issue is reliability of income data based on household surveys. For instance, validating against administrative data in the US, Meyer \& Mittag (2015) show significant underreporting of receipt and level of benefits in household surveys, between $30 \%-60 \%$ depending on the benefit type, which significantly affects poverty numbers. ${ }^{5}$ All of these issues weaken the accuracy of income poverty measures in identifying the people in poverty.

${ }^{4}$ However, see the recent efforts to improve on some of these problems based on reference budgets in the EU (Penne et al., 2016; Decerf et al., 2017), and supplemental poverty measure in the US (Short, 2011).

${ }^{5}$ The reasons for under-reporting are various including memory bias related to timing, amount or the recipient of the benefit; confusing program names; stigma and shame; and, sensitivity of income information (Meyer et al., 2009). 
Deprivation scales are raised partly as a response to these problems. These scales include multiple binary deprivation items, where each item shows deprivation in goods, services or social activities due to an inability to (economically) afford (enforced criterion). Therefore, they aim to capture deprivation in living standards due to not having adequate economic resources.

In principle, given that they are outcome measures and reflect deprivation due to affordability problems, deprivation measures are free from most of the aforementioned problems of income poverty measures. Deprivation measures represent inadequacy of economic resources for having the conditions of life necessary for social participation which, at least in theory, takes into account various sources of income such as assets and debt, in-kind benefits and public services. Also, since needs are directly evaluated, the variation in needs across individuals or households does not construe a problem if each relevant need is included into the measures. For example, variation in needs for child care can be accounted by including an item that represent cost-related unmet needs in child care. Households who do not have the need (e.g. without children), or who have the need but met (e.g. with children and get free child care) score zero, while those who have cost-related unmet need score one from the deprivation item.

However, in practice, existing deprivation scales suffer from three conceptual and four data problems, and both types of problems might cause Type I and II error in measurement (see Table 1). 
Regarding conceptual problems, the first is the data-driven design. Although relevant deprivation items are selected based on theory, deprivation scales are generally constructed based on data-driven methods (exploratory factorial techniques). Therefore, specification of resulted scales is ultimately determined by data. As explained in more detailed below, there are significant limitations in deprivation data, hence one would expect existing scales to be inadequate for capturing different experiences of poverty.

The second is the neglect of dimensionality, more specifically the use of non-zero thresholds in a unidimensional scale (Bedük, 2018b). Existing deprivation measures are designed as unidimensional scales which collapse and evaluate different types of poverty in the same scale. Non-zero thresholds (e.g. 3+) are then used to identify the most deprived and exclude non-poverty cases. Yet in such a measure, a person who is deprived only in one dimension (e.g. basic goods, health care or education access, social activities) might be wrongly identified as non-poor due to the use of non-zero thresholds. Therefore, non-zero thresholds in a unidimensional scale might exclude some poverty cases.

The third is the missing dimensions (Bedük, 2017). Due to data limitations, the existing measures cover some but not all aspects of poverty. For example, they do not consider needs related to health care, child and social care and education. As a result, people who experience poverty related to missing dimensions are not captured unless they are also deprived in existing dimensions. Beduk (2017; 2018a) show that existing deprivation scales particularly fail to identify people in poverty with needs in health care, child care, social care and education. 


\section{Table 1: Problems of existing deprivation scales and possible related measurement error}

\begin{tabular}{lccl}
\hline Problem & $\begin{array}{c}\text { Type I error - } \\
\text { overestimation }\end{array}$ & $\begin{array}{c}\text { Type II error - } \\
\text { underestimation }\end{array}$ & Proposed solution \\
\hline Conceptual problems & $X$ & $\checkmark$ & Concept-led design \\
Data-driven specification & $X$ & $\checkmark$ & Multidimensionality \\
Neglected dimensionality & $X$ & $\checkmark$ & Comprehensiveness \\
Missing dimensions & $\checkmark$ & & \\
Data problems & $\checkmark$ & $\checkmark$ & Post-hoc adjustment \\
Limited extent & $\checkmark$ & $X$ & Post-hoc adjustment \\
Cross-country equivalence & $\checkmark$ & $\checkmark$ & Post-hoc adjustment \\
Behavioral choices & & $\checkmark$ & Post-hoc adjustment \\
Reporting error & & &
\end{tabular}

In order to address these conceptual problems, the aim here is to construct a deprivation measure of poverty which is i) concept-led where the identification of dimensions, and the specification of overall design are primarily determined from the theoretical definition of poverty; ii) multidimensional where each dimension is evaluated separately with a relevant scale before reaching an overall evaluation of poverty; and iii) more comprehensive including aspects of poverty that are missing in existing deprivation scales such as needs for education and health.

Yet even if conceptual problems are solved, data problems might still cause some error in measurement.

Regarding data problems, the first is the limited extent of deprivation data. As mentioned in relation to missing dimensions problem, available comparable data in deprivation (e.g. in ECHP or EU-SILC) includes only some dimensions of 
poverty, which might cause failing to identify certain poverty experiences related to missing dimensions. Moreover, even for the existing dimensions, each type of deprivation is assessed based on only one or a few indicators. For example, in EU-SILC, food poverty (or insecurity) is indicated by one variable representing affordability of a meal with meat, chicken, fish (or vegetarian equivalent) every second day, which does not capture different aspects of food insecurity such as hunger or insecure access to adequate food (Loopstra et al. 2016). Therefore, evaluating each type of deprivation with only a few items as in existing deprivation measures might cause some underestimation or overestimation of the extent of deprivation.

The second is cross-cultural equivalence of deprivation items and measures. As also argued by Gábos \& Goedemé (2016) and Hick (2014), it is not clear whether the specific selected items or overall measures have the same social meaning in all EU countries. Kis et al. (2015), for example, argue that while 9-item overall deprivation measure is not affected by cultural differences, the attitudes towards holiday, car and saving (ability to pay unexpected expenses) vary across countries. This item-level non-invariance is particularly a concern as crosscountry variance for some items are unexpectedly high. For example, the deprivation rate for "ability to afford to buy new clothes" is $2 \%$ in Netherlands and $65 \%$ in Bulgaria; for "ability to afford a week of annual holiday away from home is $11 \%$ in Denmark and $76 \%$ in Romania; for "ability to afford to replace worn-out furniture" is $3 \%$ in Italy, while it is around $80 \%$ in Bulgaria. To a certain extent, such high rates in less affluent countries raise suspicion about the validity of 
these items as deprivation indicators; nevertheless, these items have high discriminatory powers and are the main source of limited variance within affluent countries. Therefore, the items included given their discriminatory value in affluent countries might cause an overestimation for the less affluent countries.

The third is measurement error due to behavioral choices. One main feature of direct outcome measures is that achieved outcomes reflect resource and need constraints as well as preferences. One of the main appeal of deprivation measures is their ability to distinguish constraints from preferences through the method originally proposed by Mack \& Lansley (1985). In this method, people are asked to evaluate whether a specific deprivation is a result of affordability problems or their own choice. Although such affordability questions seem to capture well the resource constraints (Hick, 2013), the subjective nature of the question might still bring certain biases in judgement. One main reason is that preferences are not formed independent of individual characteristics (e.g. economic conditions, age, health or personality etc.) or preferences might adapt to existing conditions (Halleröd, 2006; Crettaz \& Suter, 2013). As a result, certain groups such as elderly or those with low incomes are more likely to say "they do not want" certain items especially when their material situation is worse than before (Halleröd, 2006b; Hick, 2013; McKnight, 2013); or, elderly might be less likely to attribute deprivation to the shortage of money (Berthoud et al., 2006). ${ }^{6}$

6 For example, Siminski \& Yerokhin (2012) show that one-third of the variation in deprivation between elderly and non-elderly population is explained by unobserved characteristics, which they interpret as behavioral choices; on the other hand, Hildebrand 
Both of these issues might result in underestimation of poverty numbers. On the other hand, McKay (2004) also argues that some of those who lack many necessities at the same time possess other non-necessities which reflects the heterogeneity of preferences and sign an overestimation of poverty numbers.

The fourth is reporting error, for example due to social desirability bias or misinterpretation of questions. Evidence suggests that answers to sensitive questions are often distorted by social desirability bias. To avoid embarrassment and distress, individuals tend to underreport outcomes that are deemed as socially undesirable such as deprivation. For example, although Siminski \& Yerokhin (2012) find no evidence that reporting bias contributes to the agegradient in deprivation, Gundersen \& Ribar (2011) argue that food insecurity in the US is underreported due to social desirability bias. This evidence is also supported by the study of Breunig \& McKibbin (2011) which shows that individuals report higher financial difficulty in written, self-completion questionnaire than in the computer-assistant face-to-face interview as the prior is exposed to less social desirability bias due to being a more impersonal method. The effect of survey mode is a serious concern for deprivation measures as the data collection method in EU-SILC significantly varies across countries. Yet another issue is the misinterpretation of deprivation or affordability questions. As reported widely (e.g. Nolan \& Whelan, 2011: 69), deprivation can be found even on the highest income groups which might be related to misunderstandings about what is being asked in relation to deprivation items (e.g. going for a holiday) or et al. (2017) show that differences in deprivation between native and migrant population in Luxembourg can almost totally be explained by differences in resources. 
miscalculations related to affordability (Mack and Lansley, 1985), and both of these issues might cause overestimation of poverty.

To address possible biases related to data problems, a post hoc adjustment strategy is applied to the proposed deprivation measure using both income poverty and financial strain as dual criteria. This adjustment strategy is explained in the operationalization section; before that, next section focuses on elaborating the concept of poverty and its dimensions to address the conceptual problems.

\section{Elaborating the concept of poverty and its dimensions}

In this section, the conceptual meaning of poverty within relative deprivation framework is elaborated to inform the design of the measure. The main issue is to explain the meaning of participation in society (or exclusion from ordinary living patterns). Townsend developed relative deprivation framework based on a critique of the prevailing understanding of poverty at the time, so-called biological approach, in which poverty is defined as inability to afford "minimum necessaries for the maintenance of merely physical efficiency (Rowntree, 1901: 86)". Amongst many others, Townsend's main critique was on the narrow understanding of poverty as mere subsistence which isolates the phenomenon from its societal context, and ignores the demands or social obligations imposed upon individuals by the society (Townsend, 1962; 1993). Individuals, merely by being members of a society, not only have biological but also social and psychological needs which are created and sustained by the social institutions and welfare systems (Townsend, 1979: 50-59; Lister, 1990). Accordingly, Townsend defines relative 
deprivation and poverty in the context of social relationships, social participation and citizenship:

"People are relatively deprived if they cannot obtain, at all or sufficiently, the conditions of life - that is, the diets, amenities, standards and services - which allow them to play the roles, participate in the relationships and follow the customary behavior which is expected of them by virtue of membership of society. If they lack or are denied resources to obtain access to these conditions of life and so fulfill membership of society they may be said to be in poverty. People may be deprived in any or all of the major spheres of life [...] performing a variety of roles in fulfilment of social obligations (Townsend, 1993: 36)"

Relative deprivation is the inability to obtain the conditions of life or to meet certain needs required for social participation, while poverty is the inability to meet these needs due to not having enough economic resources. In this framework, social participation is defined in terms of performing expected social roles as citizens, parents, workers, friends, relatives, neighbors etc (Lister, 1990); dimensions of poverty are considered as different needs required for being able to perform social roles, while relevant deprivation items represent the conditions of life required to satisfy these needs. Townsend further elaborates these areas of need based on some instances of the poverty experience:

“... people do not just go hungry or get cold for lack of fuel or clothing. And their health is not just measurably worse for want of income. Families may 
no longer be able to go even the cheapest holiday, or invite friends to their homes, or send their children to school when money has to be provided for some special function or outing, or respond to urgent requests from church of which they are members. Old age pensioners may fail to join friends in a club or a pub because they lack resources to share the costs. Young families may become homeless because of a shortage of, or a deterioration in, public housing, or they may find they cannot maintain both the costs of a home and the costs of meeting other obligations, like travelling to find, or keep in, paid work, or caring for close elderly and disabled relatives. The balancing act becomes a nightmare. Their essential needs are defined in terms of family dishonor and social ostracism as well as individual hunger and cold (Townsend, 1993: 37)"

The needs go from basic goods (e.g. food, clothing and shelter) to other essentials such as education, health and caring as well as to more social ones such as leisure and social relationships (e.g. meeting friends, go on a holiday). These needs reflect three distinct features (as derived from Townsend's description of the poverty experience):

First, roots of these needs are not only physical but also social or psychological. This follows from Townsend's critique of the biological approach and underlies his relative deprivation approach which considers needs as socially constructed, reflecting "a range of social expectations and responsibilities, and also dictates of laws (Lister, 2004:24)". 
Secondly, these needs are considered as absolute and universal, while the conditions of life required to meet these needs are relative to the society (see also Gordon et al., 2000) as well as to individual and household characteristics (e.g. based on age, health and household demographics). This interpretation has parallels to Sen's (1983) argument that capabilities are absolute while commodities required to reach capabilities are relative, and Doyal \& Gough's (1984) theory, where basic human needs are absolute and universal while commodities to satisfy these needs are relative.

Thirdly, each need is considered as a constitutive component of poverty yet without any hierarchy among them - the value given to each dimension might vary across individuals depending on their specific conditions as well as preferences and choices. Yet there is no ex-ante assumption on which aspects are more important for participation. Therefore, it is important to consider each need separately, as when money is scarce, individuals might choose different needs to satisfy, and essentially, an enforced deprivation in even one defines a poverty experience.

Based on this framework, conceptual structure of poverty defined in Townsendian terms can be described as in Figure 1. It is a multidimensional and multi-level structure, and in psychometrics terminology a formative measure (against commonly used reflective measures) where dimensions define poverty, components define dimensions, and observed indicators reflect components. 
Dimensions represent areas of needs required for social participation, where social participation is considered as the ability to adequately fulfil responsibilities and performing social roles related to work, family and wider community. These needs are universal, absolute and essential conditions for social participation and avoiding poverty. An example could be needs for basic goods.

Components represent goods, services and activities (conditions of life) required to meet needs for social participation but might be lack due to a resource constraint (inability to economically afford). Therefore, these conditions of life are essential conditions for meeting needs for social participation and avoiding poverty. An example would be inability to afford food.

Within this framework, if someone is not able to afford one of the conditions of life (i.e. deprivation in a component), she/he is not able to meet one of the required needs for social participation (i.e. deprivation in a dimension), and hence considered as living in poverty. This perspective reflects a union approach at both levels - deprivation in a component means deprivation in a dimension, and deprivation in a dimension means poverty. Then measuring poverty comes down to measuring deprivation in components of dimensions. In other words, there are two key steps in this framework - identifying relevant dimensions and their components, and devising reliable scales for each component. The next section deals with the issue of identifying dimensions and their components. 
Figure 1: Conceptual structure of poverty defined in Towsendian terms

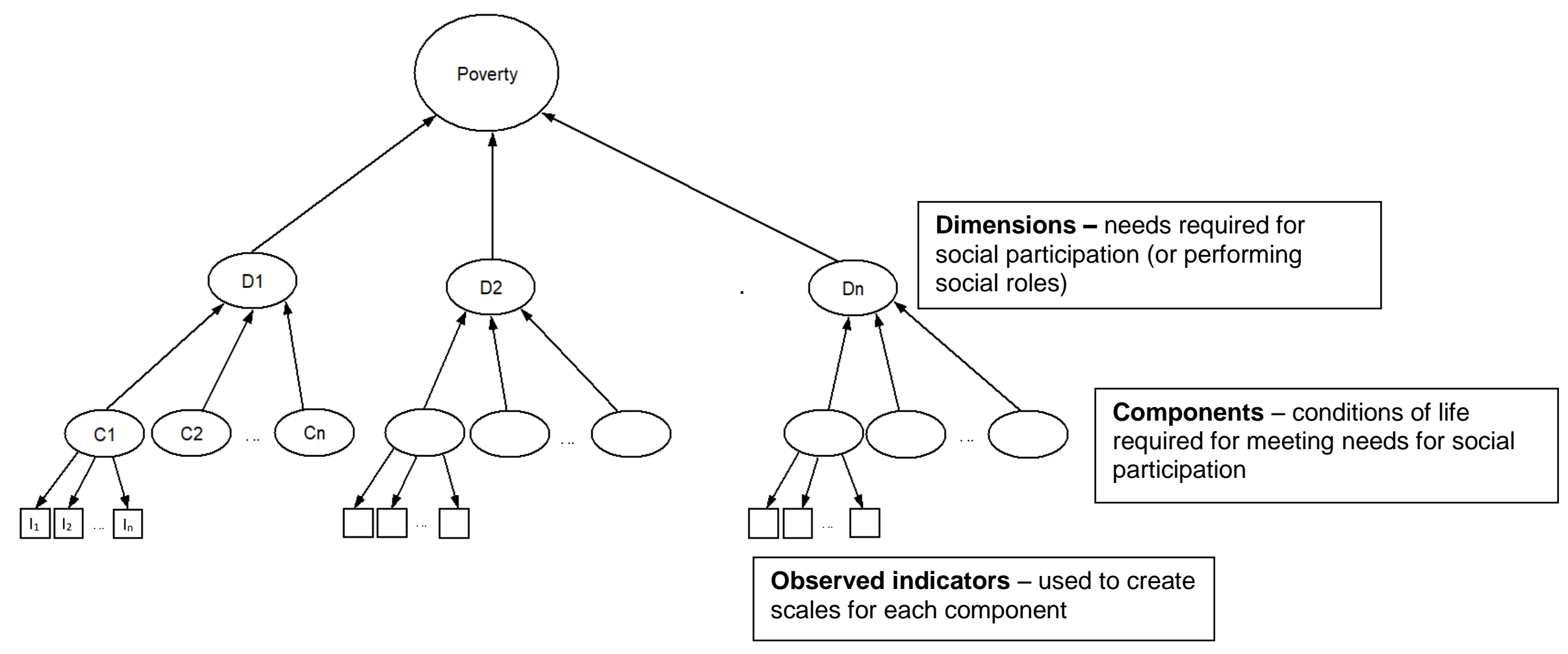




\section{Identifying dimensions of poverty and their components}

In this section, the aim is to describe a provisional list of dimensions derived mainly based on applied theoretical definition of poverty and existing empirical evidence. Such practice helps to elaborate the meaning of poverty and exemplify a poverty measure representing the conceptual structure explored above. The main criterion to identify dimensions is that the dimensions should represent areas of needs that are essential for social participation (or performing social roles), where social participation is considered more generally as the ability to adequately fulfil responsibilities related to work, family and wider community.

The meaning of each dimension is elaborated by exploring their components, where components represent conditions of life required for meeting needs for social participation but might be lack due to an economic resource constraint (i.e. inability to afford). Therefore, I briefly report some empirical evidence on the relationships between

i) needs and social participation to identify dimensions, and ii) needs and low income to identify components.

Following this framework, four dimensions are identified, namely need for basic goods, health, education, and leisure and social relationships. It is important to note here that this practice of deriving dimensions is confined to the dimensions that are possible to measure given available data. In principal, for example, needs related to caring (child and social care) or employment should also be considered. 
Basic goods. This dimension represents the need for basic goods such as food, clothing and shelter for social participation. This dimension closely resembles Rowntree's (1901) idea of absolute poverty where such goods are necessary for subsistence and physical maintenance. Recent evidence shows increasing trends in the levels of food insecurity across Europe, mostly due to financial difficulties (Loopstra et al., 2015; 2016). Food insecurity is shown to have an impact on managing chronic diseases and mental health problems (Gundersen and Ziliak, 2015; Pryor et al., 2016), and school children's academic performance and social skills (Jyoti et al., 2005). Similarly, lack of appropriate clothing is essential for keeping physical health, but also as a social status symbol, has implications for social participation in the context of work, friendship and social activities, especially for women and children (Francis, 1992; Turner-Bowker, 2001). Regarding shelter, the most immediate issue is habitancy. ${ }^{7}$ Recent evidence from an emerging area of research in the US has shown the high prevalence of eviction among inner-city poor, especially for black women, which increases the chances of job loss, family dissolution and mental health problems and brings about prolonged period of homelessness (Desmond, 2012). ${ }^{8}$ Also, recent evidence has shown that having housing arrears is linked to worse health (Clair et al. 2016). Another relevant problem related to housing is fuel poverty, which may result in deteriorations in physical and mental health (Thomson and Thomas, 2015) and affects

\footnotetext{
${ }^{7}$ Clair et al. (2018) recently proposed a measure of housing precariousness where they define four dimensions: security, affordability, quality and access to services. The conceptualization here is very similar except that it excludes access to services dimension as it is difficult to assess whether such deprivation is related to resource constraints given available data.

${ }^{8}$ In Europe, especially after 2008 mortgage crisis, eviction and housing has also become a significant concern especially for the Southern countries.
} 
everyday practices and social relations (Middlemiss and Gillard, 2015). The last aspect of housing deprivation is the inadequacy of housing facilities such as space, furniture and physical building. Reviewing evidence based on some housing interventions, Thomson \& Thomas (2015) show that improvements in domestic space and design appropriate to needs is linked to improved mental health, reduced risk of chronic illness, improved relationships and social interactions, and increased opportunities for leisure and study in the household. All these three housing problems are commonly linked to lack of money, while also affecting people's ability to take up employment (Tunstall et al., 2013). Therefore, relevant components for this dimension are inability to afford i) food, ii) clothing, iii) habitancy, iv) fuel and v) housing facilities.

Health. This dimension represents the needs related to health for social participation. Health problems are important barriers to social participation in various ways. People with poor health (e.g. self-rated bad health, having chronic health or disability problems) generally have lower employment rates, are more likely to exit employment earlier, have fewer working hours and lower earnings; also, specifically those with a disability problem are less likely to have completed upper secondary education and more likely to have dropped out of school prematurely (OECD, 2010; 2016; van Rijn et al., 2014). A recent scoping review identifies lower participation of people with disabilities in leisure activities and schools partly due to financial problems (Hästbacka et al., 2016). Although, it is hard to identify specific cases of health problems directly caused by lack of money, a recent review has shown that low income is an important determinant of health through its material, psycho-social and behavioral effects (Benzeval et al., 2014). The relevant part here is the material effect which regards the ability to afford health- 
promoting goods, avoiding harmful environment and engaging in a way of life that promotes health. ${ }^{9}$ Therefore, relevant components of this dimension are inability to afford i) health care services, ii) health-promoting goods, iii) avoiding harmful environment, and iv) a healthy diet and living style.

Education. This dimension represents the needs related to education for social participation. Education is an essential element in various aspects of participation into society. Formal educational achievement as well as cognitive and non-cognitive skills are important determinants for many important outcomes such as labor market participation and health (Conti et al., 2010), health behaviors (Cutler and Lleras-Muney, 2006), and social capital (Helliwell and Putnam, 2007). Access to higher education itself is even sometimes considered as a component of participation into society (Archer et al., 2005) and incur extra financial costs not only due to tuition fees but also related to transport, school lunches, uniform and textbooks, school trips and extracurricular activities (Bradshaw and Finch, 2002). Beyond formal education, access to information is instrumental for education and learning for young people (Davies et al., 2015), but also for adults an important medium for social engagement (Bargh and McKenna, 2004), job search (Kuhn and Mansour, 2014) and access to financial services (Claessens, 2006). In that respect, components of this dimension are ability to afford i) formal education, other goods and services that support ii) education (e.g. working space) and iii) learning of children (e.g. toys, books), and iv) provides access to information (e.g. internet).

\footnotetext{
${ }^{9}$ The psycho-social effect includes stress of economic scarcity; the behavioral effect considers the impact of low income context on health behavior, specifically on risky health behavior.
} 
Leisure and social relationships. This dimension represents the needs related to leisure and social relationship for social participation. Social and physical leisure activities increase the feelings of social support (Coleman and Iso-Ahola, 1993), and help to create social networks which can lead to enhanced social capital (Putnam, 2001; Van Ingen and Van Eijck, 2009) and better health (Smith and Christakis, 2008); while a lack of them is linked to negative health outcomes, high stress levels and social isolation (Passias et al., 2017). Therefore, leisure and social activities are essential to sustain social relationships. Moreover, having a lack of adequate economic resources has shown to have detrimental effects on relations with friends and relatives, and resource potential of networks (Mood \& Jonsson, 2016; Böhnke \& Link, 2017) and on the ability to participate in leisure activities (Bittman, 2002; Passias et al., 2017). Having sufficient leisure time is another component which is mainly determined hours of employment, family responsibilities and gender, but also affordability of leisure time. Therefore, components of this dimension are inability to (economically) afford i) having leisure time, ii) leisure activities and iii) social activities.

In Table 2, identified dimensions of poverty and their components are presented. As informed by the theoretical definition, each need is a constitutive component of poverty, without any hierarchy among them, thus deprivation in even one of them defines a poverty experience. For example, not being able to afford food or fuel defines a poverty experience, since having unmet need for basic goods prevents individuals from performing their social roles and participating in society. In the following sections, the aim is to operationalize this conceptualization and construct a multidimensional 
deprivation measure of poverty that can capture such poverty to the extent possible given available data. Data is described in the next section.

Table 2: Identified dimensions of poverty and their components

\begin{tabular}{|l|l|}
\hline Dimensions & Components \\
\hline Need for basic goods & $\begin{array}{l}\text { Inability to afford adequate } \\
\text { i) food, ii) clothing, iii) habitancy, iv) fuel and v) housing facilities }\end{array}$ \\
\hline Need for health & $\begin{array}{l}\text { Inability to afford } \\
\text { i) health care services, ii) other health-promoting goods, iii) avoiding harmful } \\
\text { environment, and iv) a healthy diet and living style }\end{array}$ \\
\hline Need for education & $\begin{array}{l}\text { Inability to afford } \\
\text { i) formal education, goods and services that ii) supports education, iii) } \\
\text { learning for children, and iv) provide access to information }\end{array}$ \\
\hline $\begin{array}{l}\text { Need for leisure and } \\
\text { social relationships }\end{array}$ & $\begin{array}{l}\text { Inability to afford } \\
\text { i) sufficient leisure time, and participating in ii) leisure and iii) social activities }\end{array}$ \\
\hline
\end{tabular}

\section{Data}

As the main data source for the contemporary poverty studies in the EU, EU-SILC 2009 survey is used. EU-SILC is a comparable microdata on living standards collected across 29 European countries. 2009 wave includes a special material deprivation module. The main survey includes deprivation indicators collected generally at the household level (e.g. ability to keep home adequately warm), while in the deprivation module, there are further questions asked at the individual (e.g. about basic needs and leisure) as well as child level (answered by the household reference person). Therefore, the items are 
collected at three different levels: household, adult and child. The details of the deprivation indicators are described at Table A1 in Appendix.

The poverty rates are calculated at the individual level. To do this, the items collected at the household level are distributed to each household member; for the items collected at the adult level, the household is considered as deprived if one adult is deprived $;{ }^{10}$ and for the items collected at the child level, a household is considered deprived if a child is deprived. Also, some items collected both at the adult and child level (e.g. holiday) are merged given the procedure explained above. Therefore, if any adult or child is deprived of a specific item, each member of the household is considered as deprived of this specific item in the proposed measure.

As shown in Table A2 in Appendix, the rate of missing for each deprivation indicator is very low (below $0.4 \%$ ) which in total corresponds to $1.7 \%$ of total sample. Although the rate of missing data varies across countries (e.g. no missing in Cyprus; $4.5 \%$ in Denmark), it is below $5 \%$ in all countries (see Table A3 in Appendix). The only exception is Sweden which has $45 \%$ missing rate and hence excluded from analysis. Also, Malta is excluded due to data problems for the variables used in the validity analysis (described further in the relevant section). Therefore the analysis includes 27 European countries, excluding Sweden and Malta.

10 This procedure, counting the household as deprived if at least one adult is deprived, is necessary as for some countries ("register countries"), the information is available only for the household reference person. On the other hand, Guio et al. (2016) counts households deprived when at least half of the household is deprived. 


\section{Operationalization of the proposed measure}

Given the proposed conceptual structure and definition of poverty, operationalization is mainly an exercise of creating reliable scales for the components of each dimension. Four distinct need areas are identified showing the necessary conditions for participating in society and performing social roles. These needs are basic goods, health, education, and leisure and social relationships. The main issue is to assess whether each need is met or unmet due to a resource constraint.

In the previous section, components of each dimension are explored, which represent the conditions of life (goods, services and activities) required to satisfy each need, but might be lack due to a resource constraint. Having an enforced deprivation in one component by definition shows an unmet need in the relevant dimension, hence an experience of poverty. For example, if an individual cannot afford health care, she/he has unmet needs for health, or is deprived in health dimension, and hence experiences poverty.

Therefore, the key issue here is to create valid scales for each component. As explained below, the scales are constructed based on three criteria, namely face, construct and criterion validity. One important shortcoming is that, due to data limitations, only some of the identified components are possible to represent with available deprivation items. Still, the proposed measure is an improvement to existing measures in terms its comprehensiveness. 


\section{Creating scales for each component}

The scales are created using three criteria. The first is face validity, mainly a subjective judgement on the extent to which a scale represents the phenomenon that it purports to measure. According to this criterion, the selected items should represent related components. Given the proposed definition, one important feature of the selected items should be representing resource constraints rather than choice. Therefore, the main test for this criterion is whether selected items show deprivation due to resource constraints.

The second is construct validity, empirically examines the extent to which a scale captures what it intends to measure. For this exercise, three validity indicators are used (see Table 3; first three rows show the main indices used, while the latter rows show the original variables out of which the three indices are derived):

i) ability to make ends meet, which is a widely used validity indicator in poverty measurement scholarship, represent individuals' own assessment about the adequacy of their resources against their needs - originally a six category measure from "with great difficulty" to "very easily", this indicator is used in a binary form, reflecting those who experience at least some difficulties making ends meet;

ii) an income threshold, $120 \%$ of median disposable equivalized income, which is sometimes used as a threshold for high income;

iii) a financial strain index, very similar to the one proposed by Whelan and Maitre (2013), which includes five indicators of self-assessed financial conditions (with a Cronbach alpha of 0.71 ), but used in in a binary form with a threshold of zero (reporting at least one deprived financial condition). 
Table 3: Descriptives for the validity indices for construct validity tests

\begin{tabular}{llllll}
\hline Variable & Mean & SD & Min & Max & N \\
\hline Main validity indices & & & & & \\
At least some difficulties making ends meet & 0.61 & 0.49 & 0 & 1 & 515992 \\
HH income below 120\% median & 0.65 & 0.48 & 0 & 1 & 515992 \\
Financial strain (1+) & 0.55 & 0.50 & 0 & 1 & 515992 \\
\hline $\begin{array}{l}\text { Original variables out of which two validity } \\
\text { indices are constructed }\end{array}$ & & & & & \\
Ability to make ends meet & 3.20 & 1.30 & 1 & 6 & 515992 \\
Financial strain index & 1.71 & 1.27 & 0 & 5 & 515992 \\
Having difficulty making ends meet & 0.29 & 0.46 & 0 & 1 & 515992 \\
Inability to pay unexpected expenses & 0.37 & 0.48 & 0 & 1 & 515992 \\
Having structural arrears & 0.12 & 0.33 & 0 & 1 & 515992 \\
Feeling heavy burden of housing cost & 0.33 & 0.47 & 0 & 1 & 515992 \\
Feeling heavy burden of debt & 0.10 & 0.30 & 0 & 1 & 515992 \\
\hline
\end{tabular}

For a scale to pass this test, a significant majority of those identified as deprived by the scale in the EU is expected to i) report at least some difficulties making ends meet, ii) have income below $120 \%$ of median income, and iii) report at least one financial strain condition. The level of "significant majority" is chosen as ideally $90 \%$ or minimum $80 \%$. This choice is relatively arbitrary yet gives only limited margin of error, which can be acceptable given data limitations.

The third is criterion validity, an empirical examination of certain abilities that are expected to be reflected by a scale. The main test for this criterion is that deprivation in a component cannot be experienced by the majority of a population. Deprivation represents an observable disadvantage relative to society an individual belongs 
(Townsend, 1987). Then, by definition, the rate of deprivation for a specific component should not exceed half of the population.

Based on these three criteria, the selected items and constructed scales are presented in Table 4. Regarding face validity, the first issue is that there are no suitable indicators for some of the identified components (e.g. healthy diet and living style) which possibly cause some underestimation. Secondly, for most of the components, number of relevant indicators is limited possibly causing under or over estimation. Thirdly, some items do not represent resource constraints, for example in harmful environment, habitancy and housing facilities scales, hence might represent preferences which also possibly cause some overestimation. ${ }^{11}$ Regarding construct validity, for all scales except harmful environment, at least $80 \%$ (and commonly above $85 \%$ ) of those identified as deprived report at least some difficulties making ends meet, have income above $120 \%$ of median, and reports at least one financial strain (see Appendix, Table A4). Regarding criterion validity, two problems are existing which possibly show some overestimation (see Appendix, Table A5). First, deprivation rates exceed 50\% for leisure activities in Bulgaria, Estonia, Greece, Hungary, Latvia, Poland, Portugal, Romania and Slovakia, and for social activities in Bulgaria and Romania. Secondly, in Bulgaria, around $70 \%$ is deprived in fuel and clothing components.

The problems related to face and criterion validity possibly reflect some error in measurement related to aforementioned issues in deprivation data:

\footnotetext{
11 To partially overcome this problem, either scales are supported by another subjective variable specifically related to resource constraints (e.g. reporting heavy burden of housing cost), or a threshold is applied on the number of deprivations to be counted as deprived for a component (e.g. harmful environment scale).
} 


\section{Table 4: Description of the measure - dimensions, components and related scales}

\begin{tabular}{|c|c|c|}
\hline Dimensions & Components & Scales for each component \\
\hline Basic goods & $\begin{array}{l}\text { Food } \\
\text { Clothing } \\
\text { Habitancy } \\
\text { Fuel } \\
\text { Housing facilities }\end{array}$ & $\begin{array}{l}\text { Food - Being deprived of at least one of the following: } \\
\text { Ability to afford } \\
\text { i. meal with meat every second day }(M) \\
\text { ii. fresh fruit and vegetables every other day }(\mathrm{C}) \\
\text { iii. three meals a day }(\mathrm{C}) \\
\text { Clothing - Being deprived of at least one of the following: } \\
\text { Ability to afford } \\
\text { i. replacing worn-out clothes (M) } \\
\text { ii. two properly fitting shoes (M) } \\
\text { Habitancy - Being deprived of at least one of the following AND reporting } \\
\text { heavy burden of housing cost: } \\
\text { i. forced to leave house due to eviction, distraint or financial difficulties; }(\mathrm{H}) \\
\text { ii. having arrears for rent or mortgage }(\mathrm{H}) \\
\text { Fuel - Being deprived of at least one of the following: } \\
\text { i. ability to afford keeping home adequately warm (H) } \\
\text { ii. having arrears for utility bills }(\mathrm{H}) \\
\text { Housing facilities - Being deprived of at least two of the following: } \\
\text { i. leaking roof, damp walls/floors/foundations, or rot in windows/floor }(\mathrm{H}) \\
\text { ii. shortage of space in dwelling }(\mathrm{H}) \\
\text { iii. ability to afford replacing worn-out furniture (e.g. chairs, tables etc.) (H) }\end{array}$ \\
\hline Health & $\begin{array}{l}\text { Health care access } \\
\text { Harmful environment }\end{array}$ & $\begin{array}{l}\text { Health care access - Being deprived of at least one of the following: } \\
\text { Ability to afford } \\
\text { i. medical examination or treatment during last } 12 \text { months }(M) \\
\text { ii. dental examination or treatment during the last } 12 \text { months }(M) \\
\text { Harmful environment - Being deprived of at least four of the following: } \\
\text { i. noise from neighbors or from street }(H) \\
\text { ii. pollution, grime or other environmental problems in local area }(H) \\
\text { iii. crime, violence and vandalism in the area }(H) \\
\text { iv. frequently litter lying around the neighborhood }(H) \\
\text { v. frequently damaged public amenities in the neighborhood }(H) \\
\text { vi. outdoor space in the neighborhood where children can play safely }(C)\end{array}$ \\
\hline Education & $\begin{array}{l}\text { Education goods } \\
\text { Learning goods } \\
\text { Information goods }\end{array}$ & $\begin{array}{l}\text { Education goods - Being deprived of at least one of the following: } \\
\text { i. ability to afford participating in school trips/event that cost money }(\mathrm{C}) \\
\text { ii. having suitable place to study / do homework at home }(\mathrm{C}) \\
\text { Learning goods - Being deprived of at least one of the following: } \\
\text { Ability to afford } \\
\text { i. books at home suitable for children's age }(\mathrm{C}) \\
\text { ii. outdoor leisure equipment or indoor games }(\mathrm{C}) \\
\text { Information goods - Being deprived of at least one of the following: } \\
\text { Ability to afford } \\
\text { i. a computer }(\mathrm{H}) \\
\text { ii. internet }(\mathrm{H})\end{array}$ \\
\hline $\begin{array}{l}\text { Leisure and } \\
\text { social } \\
\text { relationships }\end{array}$ & $\begin{array}{l}\text { Leisure activities } \\
\text { Social activities }\end{array}$ & $\begin{array}{l}\text { Leisure activities - Being deprived of at least one of the following: } \\
\text { Ability to afford } \\
\text { i. regularly participating in a leisure activity such as sport, cinema, concert etc. for } \\
\text { adults; swimming, playing an instrument for child (M) } \\
\text { ii. spending a small amount of money each week on yourself (A) } \\
\text { iii. going on a yearly holiday away from home at least one week (M) } \\
\text { Social activities - Being deprived of at least one of the following: } \\
\text { Ability to afford } \\
\text { i. getting together with friends/family for a drink/meal at least once a month (M) } \\
\text { ii. celebrations on special occasions (C) }\end{array}$ \\
\hline
\end{tabular}

Notes: (A) Adult items (C) Children items (H) Household items (M) Mixed - combined adult and childre 
i) limited number of relevant indicators cause some mismeasurement; ii) relationships of some indicators to poverty is rather weak in some countries compared to others (cross-cultural equivalence); iii) some items include error due to misunderstandings in deprivation or affordability questions (reporting error); and iv) some items reflect preferences not constraints (behavioral choice).

\section{How to mitigate error in measurement? A dual adjustment strategy}

In order to address the data problems described in Table 1 such as limited extent of data, cross-cultural equivalence, behavioral choice and reporting error, a dual adjustment strategy is applied here. The idea is to use both an income poverty measure and a self-assessed financial strain measure as criteria to correct for possible error and reach more accurate identification of poverty.

In the existing literature, alternative strategies have been applied to correct for possible error in measurement. The most common is using a non-zero threshold for each scale. For example, Guio et al. (2016) apply an ad hoc non-zero threshold on their scale mainly to limit the measurement error (e.g. those who are deprived of one to four items are not considered as in poverty). This is an ideal strategy when reliable scales with adequate number of items can be constructed. However, this strategy is not suitable here mainly due to the limited number of items available to construct each scale. For example, a non-zero threshold in the leisure activities scale, while removing some Type I error (especially for less affluent countries), might include some Type II error (especially for more affluent countries). Moreover, even in scales with adequate number 
of items, a non-zero threshold might not be empirically supported as argued by Bedük (2018b). ${ }^{12}$

Another strategy is using a non-zero threshold at the dimensional level as exemplified in the dual cut-off method of Alkire and Foster (2011) and consistent poverty approach of Maitre et al. (2013). The idea here is that deprivation in a single dimension may represent something other than poverty, and to limit measurement error a threshold can be applied on the number of deprived dimensions. This strategy is also not suitable here mainly because, based on applied theoretical definition, being deprived in one dimension amounts to a poverty experience, hence a non-zero threshold at the dimensional level would exclude some poverty cases. A similar conceptual view has also been advocated by Bourguignon and Chakravarty (2003): multidimensionality of poverty means that having a shortfall in even one dimension amounts to a poverty experience; hence, a truly multidimensional measure can only be constructed following a union approach, in other words, with a zero threshold at the dimensional level. A nonzero threshold at the dimensional level, while excluding some Type I error, would include some Type II error. In other words, a non-zero threshold at the dimensional level, as a more restrictive criterion, would identify only more severe poverty cases. Indeed, Alkire and Foster (2011) argue that using a threshold at the dimensional level helps to target "the most extensively deprived", and Maitre et al. (2013: 22) consider their consistent poverty measure primarily for "distinguishing a sub-set within that

\footnotetext{
${ }^{12}$ A non-zero threshold is applied here for some scales (e.g. harmful environment) as items in these scales do not reflect resource constraints.
} 
[target] population which merits priority in framing anti-poverty policy". ${ }^{13}$ Yet, the aim here is not to distinguish the most deprived or most disadvantaged but to identify poverty. Moreover, as recently argued by Datt (2018), applying a threshold at the dimensional level does not provide a consistent strategy to limit measurement error, as the nature of error might be discontinuous and thresholds are applied usually in an ad hoc manner.

The last strategy applied in the existing literature to limit measurement error is excluding those with high incomes (e.g. Mack and Lansley, 1985; 2015). This strategy is problematic as income measures do not account for non-income resources, savings and debt, and heterogeneity of needs (e.g. health care, child care, social care, education, transportation etc.). Thus, it is hard to identify and justify a threshold that separate those with high incomes whom are considered as non-poor.

An alternative approach can be using both an income and a self-assessed financial strain measure. Such adjustment strategy would avoid problems of using only objective income measures since the subjective financial strain measure by definition includes an evaluation of overall resources and needs by the respondent. Therefore, by using an additional self-assessed financial strain measure, one can also account for variation in non-income resources and needs across individuals and households. Using dual criteria, one objective and one subjective measure of financial situation, the aim here is to reach a more robust adjustment strategy than its previous alternatives.

\footnotetext{
${ }^{13}$ Still a consistent poverty measure with the proposed index is constructed and compared to the consistent poverty measure of Maitre et al. (2013) - see conclusion and Supplementary Material.
} 
The proposed adjustment strategy is a two-step process, first, excludes those who are wrongly identified as in poverty (Type I error), and secondly, includes those who are missed by the deprivation measure (Type II error). In the first step, a household is considered as non-poor if it does not experience income poverty (60\% of median) and does not report significant financial strain (reporting at most two out of five item) (exclusion adjustment). Similarly, in the second step, a household is considered as poor if it suffers from income poverty and significant financial strain (exclusion adjustment).

Poverty rates for each country before and after each adjustment are summarized in Table 5. The first exclusion adjustment removes, in average for the EU, half of those previously identified by the measure. The amount of removed cases significantly varies among countries, usually between $30 \%$ and $65 \%$ in relative terms, yet without any systematic pattern. ${ }^{14}$

Despite the significant numbers removed by the first adjustment, the second inclusion adjustment does not seem to significantly change the numbers. This might show that the underestimation problems (Type II) such as adaptive preferences and desirability bias are not significant matters for the proposed measure, while overestimation problems (Type I) related to cross-cultural equivalence, behavioral choices and reporting error are important. Nevertheless, most of the Type I error problems related to criterion validity seem to be resolved after the exclusion adjustment as the deprivation rate in each component in each country goes below $50 \%$ after adjustment (see Table A6 in Appendix). Therefore, the exclusion adjustment seems to effectively mitigate Type

\footnotetext{
${ }^{14}$ Only in absolute terms, the amount removed by adjustment is higher in countries with higher initial poverty rate.
} 
I errors. In the following section, this claim is examined further by testing the overall validity of the (adjusted) proposed measure before evaluating the overall validity of the proposed measure against EU 2020 poverty target measure.

Table 5: Poverty rates for each country before and after each adjustment

\begin{tabular}{cccccc}
\hline & $\begin{array}{c}\text { Base } \\
\text { measure }\end{array}$ & $\begin{array}{c}\text { Exclusion } \\
\text { adj. }\end{array}$ & $\begin{array}{c}\text { Inclusion } \\
\text { adj. }\end{array}$ & $\begin{array}{c}\text { Absolute } \\
\text { change }\end{array}$ & $\begin{array}{c}\text { Relative } \\
\text { change }\end{array}$ \\
\hline AT & 0.42 & 0.15 & 0.15 & 0.26 & 0.64 \\
BE & 0.39 & 0.19 & 0.19 & 0.19 & 0.50 \\
BG & 0.92 & 0.50 & 0.50 & 0.42 & 0.45 \\
CY & 0.64 & 0.43 & 0.44 & 0.20 & 0.31 \\
CZ & 0.54 & 0.19 & 0.19 & 0.35 & 0.65 \\
DE & 0.46 & 0.17 & 0.17 & 0.28 & 0.62 \\
DK & 0.21 & 0.07 & 0.07 & 0.13 & 0.64 \\
EE & 0.63 & 0.25 & 0.25 & 0.38 & 0.60 \\
EL & 0.65 & 0.34 & 0.34 & 0.31 & 0.47 \\
ES & 0.51 & 0.29 & 0.29 & 0.22 & 0.43 \\
FI & 0.25 & 0.12 & 0.12 & 0.13 & 0.52 \\
FR & 0.45 & 0.20 & 0.20 & 0.24 & 0.55 \\
HU & 0.80 & 0.42 & 0.42 & 0.38 & 0.48 \\
IE & 0.50 & 0.26 & 0.27 & 0.23 & 0.47 \\
IT & 0.57 & 0.31 & 0.31 & 0.26 & 0.45 \\
LT & 0.76 & 0.34 & 0.34 & 0.41 & 0.55 \\
LU & 0.28 & 0.14 & 0.14 & 0.14 & 0.49 \\
LV & 0.84 & 0.45 & 0.45 & 0.39 & 0.46 \\
NL & 0.25 & 0.09 & 0.09 & 0.16 & 0.65 \\
PL & 0.74 & 0.33 & 0.33 & 0.41 & 0.56 \\
PT & 0.73 & 0.28 & 0.28 & 0.44 & 0.61 \\
RO & 0.91 & 0.41 & 0.41 & 0.50 & 0.55 \\
SI & 0.51 & 0.26 & 0.26 & 0.25 & 0.49 \\
SK & 0.71 & 0.24 & 0.24 & 0.47 & 0.66 \\
UK & 0.44 & 0.20 & 0.20 & 0.24 & 0.54 \\
\hline Total & 0.54 & 0.25 & 0.25 & 0.29 & 0.53 \\
\hline & & & & & \\
\hline
\end{tabular}

Notes: The table shows the incidence of poverty in each country (the ratio of people in poverty in the population) before and after each adjustment 


\section{Examining the validity of the proposed measure}

The validity of the proposed measure is examined relatively against EU 2020 poverty target measure using a multinomial logistic model. The aim is to see which measure identifies better the groups that are theoretically and empirically expected to be in poverty. For example, given the definition of poverty above, we would expect those with lower resources and higher needs to be more likely to experience poverty. Also, it is important to consider the country profiles of the groups identified by each measure. As shown below, despite a significant agreement between the two measures, there is still substantial amount of people identified only by one measure. The idea is to compare the group identified only by proposed measure to the group identified only by EU measure based on their resources and needs.

The EU 2020 poverty target measure and explanatory variables used in regression analyses are presented in Table 6 . The EU's 2020 poverty target measure includes a material deprivation index, an income poverty and a low work-intensity measure. Recently a 13-item material deprivation index proposed by Guio et al. (2016) is endorsed by the EU to replace the old 9-item measure (Atkinson et al., 2017). This new deprivation index is used here to construct the new EU formal poverty measure. The income poverty measure is the commonly used relative measure which defines those with household disposable incomes below $60 \%$ of median income as in poverty. The households with low work intensity are defined as those with working-age members worked less than $20 \%$ of their potential in the previous year. Being identified by either of these three measures are considered as living in poverty by the EU measure. 
Given critiques about the use of low-work intensity indicator within the EU poverty target, the analysis is replicated with a poverty target measure that includes only income poverty and material deprivation measures. The results, presented in Table A9 in Appendix, (which are very similar to the main analysis and provides even stronger evidence that the proposed measure captures a more disadvantaged group than the EU measure even when low work intensity indicator is not included).

Table 6: The variables used in the regression analysis

\begin{tabular}{|c|c|c|c|c|c|}
\hline Variable & Mean & SD & Min & Max & $\mathbf{N}$ \\
\hline \multicolumn{6}{|l|}{ Poverty measures } \\
\hline EU 2020 poverty target & 0.26 & 0.44 & 0 & 1 & 515992 \\
\hline 13 item index (7+ deprived items) & 0.13 & 0.33 & 0 & 1 & 515992 \\
\hline Income poverty (60\% median) & 0.16 & 0.36 & 0 & 1 & 515992 \\
\hline Low work intensity & 0.06 & 0.24 & 0 & 1 & 515992 \\
\hline \multicolumn{6}{|l|}{ Explanatory variables } \\
\hline \multicolumn{6}{|l|}{ Resources } \\
\hline HRP Social class (ESEC 5) & 3.04 & 1.71 & 1 & 6 & 193639 \\
\hline HRP Education (ISCED) & 2.07 & 0.77 & 1 & 3 & 193639 \\
\hline Unemployed in $\mathrm{HH}$ & 0.10 & 0.31 & 0 & 1 & 193639 \\
\hline Tenant & 0.18 & 0.38 & 0 & 1 & 193639 \\
\hline \multicolumn{6}{|l|}{ Needs } \\
\hline Disability in $\mathrm{HH}$ & 0.39 & 0.49 & 0 & 1 & 193639 \\
\hline Chronic health pr. In HH & 0.46 & 0.50 & 0 & 1 & 193639 \\
\hline Self-rated bad health in $\mathrm{HH}$ & 0.19 & 0.39 & 0 & 1 & 193639 \\
\hline Child aged $0-2$ in $\mathrm{HH}$ & 0.07 & 0.26 & 0 & 1 & 193639 \\
\hline Child aged 3-4 in $\mathrm{HH}$ & 0.05 & 0.21 & 0 & 1 & 193639 \\
\hline Child aged 5-11 in HH & 0.14 & 0.35 & 0 & 1 & 193639 \\
\hline Child aged $12-15$ in $\mathrm{HH}$ & 0.11 & 0.31 & 0 & 1 & 193639 \\
\hline Single parenthood & 0.04 & 0.19 & 0 & 1 & 193639 \\
\hline Extended family & 0.07 & 0.26 & 0 & 1 & 193639 \\
\hline HRP Divorced / separated & 0.11 & 0.31 & 0 & 1 & 193639 \\
\hline HRP female & 0.40 & 0.49 & 0 & 1 & 193639 \\
\hline
\end{tabular}

Notes: The main models include, in addition to the variables above, country fixed-effects. 
The explanatory variables, which can be considered as risk factors, represent either resources or needs. For example, social class and education are long argued to be good determinants of long-term command over resources (Hauser \& Warren, 1997; Bollen et al., 2007). Others such as unemployment and tenancy are more immediate indicators of economic conditions.

Given the model includes these resources variables, variables such as chronic health, disability or self-reported bad health problem in the household show the effect of having extra needs and costs for health care, while having children aged 3-4, 5-11, $12-15$ in the household reflect the needs and costs related to child bearing such as those related to education. These variables represent extra care responsibilities in the household which might result in limited earning potential especially for women (Beduk, 2017). Other demographic characteristics such as single parenthood, extended family and marital status proxy experiences of specific life events, where the balance of resources and needs tend to be difficult to sustain. Country fixed effects are also included to examine country profiles captured by each measure. Age and gender of the household reference person are included as controls.

As shown in Table A7 in Appendix, missing data for poverty measures are very low (below $0.4 \%$ ) yet with the exception of 13 -item Guio index and EU 2020 poverty target having around $1.7 \%$ of the total population, which corresponds to missing data in deprivation indicators, hence excluded from the analysis. As shown in Table A8 in Appendix, missing rate for explanatory variables are also very low, where it is highest for education (2\%) and social class (1.3\%); still in total, the missing rate for all variables corresponds to $3.6 \%$ of the household sample. The missing in social class is mainly due 
to Malta, where the missing rate is $\% 21$. Also, in Malta, the social class variable has a coding problem as the country seems to have only salariat, intermediate employee and never worked. Therefore, Malta is also excluded from the analysis.

The unit of analysis for the regression analyses is household using information of household reference person (HRP) (similar to previous analogous analyses, for example by Whelan \& Maître (2012)). This is because most of the deprivation indicators are collected at the household level, which in an individual level analysis might cause clustering. Also, using HRP allows to include individual level factors such as social class and education. The analysis is run for the whole sample with country fixed effects.

\section{Comparing to EU 2020 poverty target}

The results for the proposed multidimensional deprivation measure and the EU 2020 poverty target measure are presented at Table 7 . The average rate for the proposed measure is $25 \%$ and for the EU 2020 target is $24 \%$. The variances and ranges are similar in both measures. Compared to the new EU 2020 measure, the proposed poverty measure has usually lower rates in more affluent countries such as Denmark, Finland and Netherlands, and similar or higher rates in less affluent countries such as Hungary and Latvia (except Bulgaria and Romania).

The agreement between the two measures is very high, in average around $86 \%$. The amount of agreement varies across countries with a relatively low variance - lowest in Cyprus with $70 \%$ and highest in Germany with $91 \%$. The rate of agreement seems to be lower for less affluent countries, possibly due to the fact that deprivation are much more widespread in less affluent countries. 
Table 7: Proposed measure vs. EU 2020 poverty target - mismatch

\begin{tabular}{|c|c|c|c|c|c|}
\hline Country & $\begin{array}{c}\text { Proposed } \\
\text { measure } \\
\text { - rate }\end{array}$ & $\begin{array}{c}\text { New EU } \\
2020- \\
\text { rate }\end{array}$ & Agreement & $\begin{array}{c}\text { Only } \\
\text { proposed }\end{array}$ & $\begin{array}{l}\text { Only } \\
\text { EU } \\
2020\end{array}$ \\
\hline AT & 0.15 & 0.17 & 0.90 & 0.04 & 0.06 \\
\hline $\mathrm{BE}$ & 0.19 & 0.20 & 0.88 & 0.06 & 0.07 \\
\hline$B G$ & 0.50 & 0.56 & 0.81 & 0.07 & 0.12 \\
\hline CY & 0.43 & 0.20 & 0.70 & 0.27 & 0.04 \\
\hline CZ & 0.18 & 0.14 & 0.88 & 0.08 & 0.04 \\
\hline $\mathrm{DE}$ & 0.17 & 0.21 & 0.91 & 0.03 & 0.06 \\
\hline DK & 0.07 & 0.16 & 0.88 & 0.02 & 0.11 \\
\hline EE & 0.25 & 0.24 & 0.89 & 0.06 & 0.05 \\
\hline EL & 0.34 & 0.26 & 0.83 & 0.13 & 0.05 \\
\hline ES & 0.29 & 0.23 & 0.81 & 0.12 & 0.07 \\
\hline $\mathrm{FI}$ & 0.12 & 0.16 & 0.88 & 0.04 & 0.08 \\
\hline $\mathrm{FR}$ & 0.20 & 0.19 & 0.88 & 0.07 & 0.06 \\
\hline $\mathrm{HU}$ & 0.42 & 0.35 & 0.79 & 0.14 & 0.07 \\
\hline IE & 0.27 & 0.25 & 0.83 & 0.09 & 0.08 \\
\hline IT & 0.31 & 0.25 & 0.82 & 0.12 & 0.05 \\
\hline LT & 0.34 & 0.33 & 0.84 & 0.08 & 0.07 \\
\hline LU & 0.14 & 0.18 & 0.90 & 0.03 & 0.07 \\
\hline LV & 0.45 & 0.42 & 0.84 & 0.09 & 0.07 \\
\hline NL & 0.09 & 0.15 & 0.90 & 0.02 & 0.08 \\
\hline PL & 0.33 & 0.29 & 0.85 & 0.10 & 0.05 \\
\hline PT & 0.28 & 0.30 & 0.87 & 0.06 & 0.07 \\
\hline RO & 0.41 & 0.53 & 0.81 & 0.04 & 0.16 \\
\hline SI & 0.26 & 0.17 & 0.83 & 0.13 & 0.04 \\
\hline SK & 0.24 & 0.20 & 0.86 & 0.09 & 0.05 \\
\hline UK & 0.20 & 0.23 & 0.86 & 0.06 & 0.09 \\
\hline Mean & 0.25 & 0.24 & 0.86 & 0.07 & 0.07 \\
\hline Variance & 0.19 & 0.19 & 0.12 & 0.07 & 0.06 \\
\hline
\end{tabular}

Regarding disagreement, $7 \%$ of the EU population is identified only by the proposed measure and another $7 \%$ is identified only by the EU measure. The rate of disagreement varies across countries. The amount of people identified only by the proposed measure is usually higher in less affluent countries such as Hungary and Greece (again Romania and Bulgaria are exceptions), while the amount of people 
identified only by the EU measure are significantly higher in more affluent countries such as Denmark, Finland, Luxembourg.

The question is which measure identifies more accurately the groups that are expected to be in poverty given their resources and needs. To examine this, a multinomial logit model is applied. The dependent variable is constructed based on four categories: i) not identified by both measures (none), ii) identified both by the proposed and the EU measure (both); iii) identified only by the proposed measure (only deprived), iv) identified only by the EU measure (only EU). The base outcome category is chosen as those identified only by the EU measure. The idea is to compare the profiles of those identified only by the EU measure to those identified only by the deprivation measure based on the risk factors. The results for main explanatory variables are presented in Table 8. The coefficients show relative risk ratios.

In the first column, the comparison is between those identified only by the EU measure and those identified by none. Considering the significance of coefficients, the group captured only by EU measure is significantly different than those identified by none. As would be expected, those identified only by the EU measure in general tend to have lower resources and higher needs compared to those identified by none. For example, those not identified are significantly less likely to have lower social classes and education, and to have health problems in the household. Yet there are two interesting results. First, for those who have at least a child younger than twelve and those who have at least one member with a chronic health problem in the household are equally likely to be identified only by the EU measure or identified by none. Secondly, those 
living extended family households are more likely to be not identified by both measures than being identified only by the EU measure.

Table 8: Comparing the proposed measure and the EU 2020 poverty target measure based on identified risk factors - relative risk ratios

\begin{tabular}{|c|c|c|c|}
\hline \multicolumn{4}{|c|}{ Multinomial logit $/$ Base outcome $=$ New EU 2020 only } \\
\hline & None & Both & Proposed only \\
\hline \multicolumn{4}{|l|}{ Resource indicators } \\
\hline \multicolumn{4}{|c|}{ HRP Social class (ref=Salariat) } \\
\hline Intermediate & $0.888^{*}$ & $1.381^{* * *}$ & $1.384^{\star \star \star}$ \\
\hline Small self-emp. & $0.387^{\star \star \star}$ & $2.002^{\star * *}$ & $0.624^{\star * *}$ \\
\hline Non-manual labor & $0.670^{\star \star *}$ & $1.765^{\star \star *}$ & $1.285^{\star \star}$ \\
\hline Manual labor & $0.567^{\star \star \star}$ & $1.909^{* * *}$ & $1.185^{\star *}$ \\
\hline Never worked & $0.202^{\star \star \star}$ & $1.525^{\star \star \star}$ & $0.389^{\star \star *}$ \\
\hline \multicolumn{4}{|c|}{ HRP Education (ref=Third level) } \\
\hline Upper secondary & $0.768^{\star * *}$ & $1.217^{* * *}$ & 1.117 \\
\hline Low second/Primary/Pre & $0.588^{* * *}$ & $1.731^{* * *}$ & 1.100 \\
\hline Unemployed in $\mathrm{HH}$ & $0.440^{\star \star \star}$ & $2.164^{* * *}$ & 1.052 \\
\hline Tenant & $0.686^{* \star *}$ & $1.949^{* * *}$ & $1.528^{* * *}$ \\
\hline \multicolumn{4}{|l|}{ Need indicators } \\
\hline Disability in HH & $0.794^{* * *}$ & $1.174^{* * *}$ & 1.086 \\
\hline Chronic health pr. in $\mathrm{HH}$ & 0.946 & 0.982 & 1.049 \\
\hline Bad subj. health & $0.736^{* * *}$ & $1.529^{\star \star \star}$ & $1.249^{* * *}$ \\
\hline Child aged $0-2$ in $\mathrm{HH}$ & 0.901 & $1.287^{* *}$ & 1.179 \\
\hline Child aged $3-4$ in $\mathrm{HH}$ & 1.059 & $1.276^{\star *}$ & $1.240^{*}$ \\
\hline Child aged 5-11 in $\mathrm{HH}$ & 0.986 & $1.313^{* * *}$ & $1.342^{* \star *}$ \\
\hline Child aged 12-15 in $\mathrm{HH}$ & $1.129^{*}$ & $1.634^{\star * *}$ & $1.488^{\star * *}$ \\
\hline Single parent household & $0.452^{* \star *}$ & 1.096 & $0.809^{*}$ \\
\hline Extended family & $1.429^{\star \star \star}$ & 1.030 & $1.429^{\star \star \star}$ \\
\hline HRP divorced/separated & $0.750^{\star * *}$ & $1.376^{* * *}$ & $1.197^{* *}$ \\
\hline HRP Female & $0.782^{* * *}$ & $1.231^{* \star *}$ & $1.162^{* \star *}$ \\
\hline
\end{tabular}

In the second column, the comparison is between those identified only by the EU measure and those identified by both the EU and the proposed measure. Again as expected, those identified by both measures tend to have lower resources and higher 
needs. For example, they are more likely to be in lower classes, have at least one unemployed person or a person with health problems or children in the household. Again, there are two exceptions. Those who have at least one person with a chronic problem in the household and those who have an extended family household are equally likely to be identified by only the EU measure or by both measures.

In the third column, the comparison is between those identified only by the EU measure and those identified only by the proposed measure. In general, the results show that those identified by the proposed measure are more likely to have lower resources and higher needs compared to those identified only by the EU measure.

Considering resource indicators, for example social class, those in the intermediate, non-manual and manual classes (compared to salariat class) are significantly more likely to be identified only by the proposed measure. On the other hand, small selfemployed and never worked are significantly more likely to be identified only by the EU measure. This might be related to i) the specific situation of self-employed in terms of cash income, and ii) the heterogeneous composition of the never worked group which includes individuals with different economic statuses such as long-term unemployed, students, domestic workers and other inactive. Both of these might specifically be captured by the income poverty and low work intensity components of the EU measure. Regarding other resource indicators, those who are tenant are also significantly more likely to be captured only by the proposed measure.

The differences are even greater on the needs side. Households with health problems, with children aged 3-15, those living with extended family, with a divorced or separated, 
or a female household reference person are also more likely to be captured only by the proposed measure. Only single parenthood is more likely to be captured by the EU compared to the proposed measure.

In addition to resource and need profiles, one can also examine, controlling for the individual factors, from which countries each measure is more likely to capture people. It would be expected that more people in poverty live in less affluent than more affluent countries. In Table 9, the coefficients of the country fixed effects are presented. The country fixed-effects show the location of groups picked up by each measure compared to the other.

Starting from the second column, where those identified by both measures are compared to those identified only by the EU measure, almost in all countries, it is significantly more likely to be identified by both measures than being identified only by the EU measure. The only exceptions are Denmark, Finland and Netherlands. Individuals living in these countries are more likely to be identified by the EU measure than being identified by both measures.

Similarly, as shown in the third column, the proposed measure is significantly less likely to identify people from Denmark, Finland, and Netherlands, and significantly more likely to identify people from less affluent countries compared to the EU measure. For example, compared to those identified only by the EU measure, those identified only by the proposed measure are around 8 times more likely to be in Hungary, 7.5 times more likely to be in Greece, and 4.5 times more likely to be in Bulgaria or Hungary (relative to being in Austria). 
Table 9: Country profiles captured by each measure

\begin{tabular}{|c|c|c|c|}
\hline \multicolumn{4}{|c|}{ Multinomial logit / Base outcome = New EU 2020 only } \\
\hline & None & Both & Proposed only \\
\hline \multicolumn{4}{|c|}{ Country $(r e f=A T)$} \\
\hline $\mathrm{BE}$ & $0.796^{* *}$ & 1.017 & $1.476^{\star *}$ \\
\hline$B G$ & $0.240^{* * *}$ & $3.207^{* * *}$ & $1.484^{\star *}$ \\
\hline CY & 1.116 & $4.301^{* * *}$ & $17.141^{\star * *}$ \\
\hline $\mathrm{CZ}$ & $1.614^{\star * *}$ & $1.763^{\star * *}$ & $4.277^{\star \star \star}$ \\
\hline DE & 0.911 & $1.726^{\star \star *}$ & 0.783 \\
\hline DK & $0.550^{* * *}$ & $0.276^{\star * *}$ & $0.233^{\star * *}$ \\
\hline EE & 0.866 & $2.721^{\star * *}$ & $2.012^{\star \star \star}$ \\
\hline EL & $1.637^{\star \star *}$ & $3.731^{* * *}$ & $10.101^{* \star *}$ \\
\hline ES & 0.999 & $1.403^{\star * *}$ & $4.386^{\star \star \star}$ \\
\hline $\mathrm{FI}$ & $0.681^{* * *}$ & $0.553^{* * *}$ & $0.759^{*}$ \\
\hline FR & $1.195^{\star}$ & $1.266^{*}$ & $2.203^{* \star *}$ \\
\hline $\mathrm{HU}$ & $0.614^{* * *}$ & $2.542^{\star \star *}$ & $4.665^{\star \star \star}$ \\
\hline IE & 0.845 & 1.213 & $2.502^{\star \star \star}$ \\
\hline IT & $1.281^{* * *}$ & $2.110^{* * *}$ & $6.164^{\star \star *}$ \\
\hline LT & $0.604^{\star * *}$ & $2.943^{* * *}$ & $2.846^{\star * *}$ \\
\hline LU & 1.059 & 0.825 & 0.833 \\
\hline LV & $0.588^{* * *}$ & $4.139^{* * *}$ & $2.856^{\star * *}$ \\
\hline NL & $0.813^{*}$ & $0.505^{\star * *}$ & $0.531^{* * *}$ \\
\hline PL & 0.977 & $3.471^{* * *}$ & $5.051^{* \star *}$ \\
\hline PT & 1.119 & $1.455^{\star *}$ & $1.869^{* * *}$ \\
\hline RO & $0.249^{* * *}$ & $2.042^{* * *}$ & 0.855 \\
\hline SI & 1.051 & $2.623^{\star * *}$ & $5.725^{\star * *}$ \\
\hline SK & 1.183 & $2.343^{\star * *}$ & $4.281^{* * *}$ \\
\hline UK & $0.556^{* * *}$ & 0.868 & 1.094 \\
\hline
\end{tabular}

In sum, these findings show that i) the proposed measure is more likely to capture more disadvantaged risk groups who tend to have lower resources and higher individual and household needs; and, ii) the proposed measure is more likely to capture individuals from less affluent countries compared to the EU measure. All these results support the claim that the proposed measure is more likely to identify the people in poverty than the EU poverty target measure. 


\section{Conclusion}

This paper focused on constructing a multidimensional deprivation measure of poverty that can possibly mitigate given available data the problems of existing deprivation scales. It is argued that deprivation measure can alone be used to assess poverty, both conceptually and empirically, yet with certain improvements. The paper identified three conceptual problems of existing measures such as missing dimensions, data-driven specification and neglecting multidimensionality; and three practical data issues such as cross-cultural equivalence, behavioral choice and reporting error. These problems, it is argued, can directly cause measurement errors, either underestimation (Type II error) or overestimation (Type I error).

The proposed measure has four distinct design features compared to the existing ones. First, it is a concept-led measure, where measurement design is primarily determined by the definition of poverty. To do this, a substantial part of the analysis is devoted to elaborating the meaning of poverty defined within the relative deprivation framework. Through this conceptual analysis, the dimensions are conceptually derived prior to measurement drawing on the elaborated definition of poverty and related empirical evidence. Dimensions of poverty are defined as the needs that are necessary for performing social roles and social participation, and components of these dimensions are defined as the conditions of life required to satisfy these needs which might be lack due to resource constraints.

Secondly, the measure is more comprehensive compared to its existing counterparts including dimensions such as needs related to health and education. Despite this 
improvement, the measure is still limited due to availability of data, since i) other possible dimensions such as needs related to caring, and personal and political security are missing, ii) the scales created for the components are restricted and includes only a small number of indicators, and iii) some components could be not measured given data limitations (e.g. those related to health-promoting goods, and health diet and living style).

Thirdly, as Bourguignon \& Chakravarty (2003) put it, it is a "truly multidimensional measure", where each dimension is evaluated separately and then aggregated with a zero threshold to reach the total poverty measure. In other words, being deprived in at least one dimension qualifies an individual for being counted as in poverty (union approach). This choice is again derived from the theoretical definition of poverty. Not being able to meet an identified need due to a resource constraint prevents people from performing their social roles and participating in society. As shown in supplementary material, evaluating each dimension separately improves the accuracy of measurement in multiple ways. A sizable group of people is identified only by one dimension whom are generally missed by the existing deprivation scales due to their unidimensional design. Also, the groups captured by each dimension have distinct characteristics reflecting dimension-specific deprivation conditions. For example, those with long-term health problems are more likely to be captured by the health dimension which accounts extra costs and needs related to health care. Similarly, those households with children are more likely to be captured by education dimension which considers enforced deprivations of educational goods and services. In other words, accounting for 
multidimensionality helps to capture different experiences of poverty which is otherwise neglected when different types of poverty are collapsed into one scale.

Lastly, the measure is adjusted using dual criteria of income poverty and self-assessed financial strain. This adjustment strategy is applied mainly to correct for possible underestimation or overestimation due to suspicions about the quality of data, regarding its equivalence across countries, its robustness to differences in behavioral choices and reporting error. The results of the adjustment show that the main issue is related to overestimation of poverty numbers either due to cross-cultural equivalence (e.g. meaning of holiday for social participation), reporting error (misunderstandings of the deprivation or affordability questions) or limited extent of data (inadequate number of items for each type of deprivation).

The validity of the proposed measure is assessed against the EU's 2020 poverty target measure using a multinomial logistic model. The results show that the proposed measure is more likely to capture those with needs (e.g. health problems, and those related to child bearing, or specific life-event situations such as divorce) and lower resources (e.g. social class, house ownership), and also much less likely identify people from affluent countries such as Denmark, Finland and Netherlands, and more likely to identify people from less affluent countries such as Greece and Hungary compared to the EU measure.

This measure is designed primarily for the identification of people in poverty yet can be developed further using Alkire-Foster method to create a poverty index that can account both incidence and intensity of poverty. Also, if the aim is to focus on the most 
disadvantaged, the unadjusted multidimensional measure can be combined with an income poverty measure to construct a consistent poverty measure. As shown in Supplementary Material, such a consistent poverty measure, compared to the one proposed by Whelan et al. (2013), captures an additional group who is predominantly working class or never worked, and more likely to report difficulties making ends meet and financial strain compared to the EU average.

In sum, the analysis shows that summary formats using only few key deprivation indicators are not a panacea to the problems of poverty measurement. We need concept-led, comprehensive and multidimensional measures. Beyond its better empirical performance, there are various other advantages of using a concept-led, comprehensive and multidimensional measure. Such a measure forces us to be more elaborate about our definition of poverty (i.e. defining dimensions clarifies what is meant by poverty) and guides the empirical measure which strengthen the link between concept and measure, hence the empirical validity of measures. Moreover, given its multidimensional design combined with a union aggregation strategy, the measure is decomposable to its components, which makes it easier distinguish the sources of overall poverty (see e.g. Supplementary Material - section S1). Also, having separate scales for each dimension allow us to focus on specific types of poverty, which makes it suitable for policy analysis. For example, one could evaluate the extent of food or fuel poverty and examine its relationship to other types of poverty or overall poverty.

Despite providing some solutions to the proposed problems, the applied adjustment strategy is ad hoc, and assessing its effectiveness is rather difficult. Further analysis is required to question the issues related to the validity of deprivation data, especially 
regarding overestimation (Type I error) to reach more robust poverty measures constructed based on deprivation indicators. Especially, more attention on the issues related to limited extent of deprivation data and cross-cultural equivalence are of utmost importance. 


\section{Acknowledgments}

This research was made possible by Barnett Scholarship granted towards my DPhil by the Department of Social Policy and Intervention, University of Oxford. I owe thanks to Erzsébet Bukodi, Brian Nolan and Christopher Whelan for their valuable comments on the draft of the paper.

\section{References}

Archer L, Hutchings M and Ross A (2005) Higher education and social class: Issues of exclusion and inclusion. Routledge.

Atkinson T, Guio AC and Marlier E (2017) Monitoring social inclusion in Europe. Eurostat Statistical.

Bargh JA and McKenna KYA (2004) The Internet and social life. Annu. Rev. Psychol., Annual Reviews 55: 573-590.

Bedük, S. (2017). Measuring poverty in the EU: Investigating and improving the empirical validity in deprivation scales of poverty (PhD thesis). University of Oxford.

Bedük, S. (2018a). Missing the Unhealthy? Examining Empirical Validity of Material Deprivation Indices (MDIs) Using a Partial Criterion Variable. Social indicators research, 135(1), 91-115.

Bedük, S. (2018b). Understanding Material Deprivation for 25 EU Countries: Risk and Level Perspectives, and Distinctiveness of Zeros. European Sociological Review, 34(2), 121-137.

Benzeval M, Bond L, Campbell M, et al. (2014) How does money influence health? Joseph Rowntree Foundation. 
Berthoud R and Bryan M (2011) Income, deprivation and poverty: a longitudinal analysis. Journal of Social Policy 40(01): 135-156.

Berthoud R, Blekesaune M and Hancock R (2006) Are Poor Pensioners Deprived?. Department for Work and Pensions Report no. 364.

Bickel G, Nord M, Price C, et al. (2000) Guide to measuring household food security. Revised.

Bittman M (2002) Social Participation and Family Welfare: The Money and Time Costs of Leisure in Australia. Social Policy \& Administration, Blackwell Publishers Ltd 36(4): 408-425. Available from: http://dx.doi.org/10.1111/1467-9515.t01-1-00262.

Böhnke P and Link S (2017) Poverty and the Dynamics of Social Networks: An Analysis of German Panel Data. European Sociological Review 33(4): 615-632. Available from: http://dx.doi.org/10.1093/esr/jcx063.

Bollen KA, Glanville JL and Stecklov G (2007) Socio-economic status, permanent income, and fertility: A latent-variable approach. Population studies, Taylor \& Francis 61(1): 15-34.

Bourguignon F and Chakravarty SR (2003) The measurement of multidimensional poverty. Journal of Economic inequality, Springer 1(1): 25-49.

Bradshaw J and Finch N (2002) A comparison of child benefit packages in 22 countries. Corporate Document Services.

Breunig R and McKibbin R (2011) The effect of survey design on household reporting of financial difficulty. Journal of the Royal Statistical Society: Series A (Statistics in Society), Blackwell Publishing Ltd 174(4): 991-1005. Available from: http://dx.doi.org/10.1111/j.1467-985X.2011.00696.x. 
Claessens S (2006) Access to financial services: A review of the issues and public policy objectives. The World Bank Research Observer, Oxford University Press 21(2): 207-240.

Clair A, Reeves A, Loopstra R, McKee M, Dorling D, \& Stuckler D (2016) The impact of the housing crisis on self-reported health in Europe: multilevel longitudinal modelling of 27 EU countries. The European Journal of Public Health, 26(5), 788793.

Clair, A., Reeves, A., McKee, M., \& Stuckler, D. (2018). Constructing a housing precariousness measure for Europe. Journal of European Social Policy, https://doi.org/10.1177/0958928718768334

Coleman D and Iso-Ahola SE (1993) Leisure and health: The role of social support and self-determination. Journal of leisure research, National Recreation and Park Association 25(2): 111.

Conti G, Heckman J and Urzua S (2010) The education-health gradient. The American economic review, NIH Public Access 100(2): 234.

Copeland P and Daly M (2012) Varieties of poverty reduction: Inserting the poverty and social exclusion target into Europe 2020 1. Journal of European Social Policy, SAGE Publications Sage UK: London, England 22(3): 273-287.

Crettaz E and Suter C (2013) The impact of adaptive preferences on subjective indicators: An analysis of poverty indicators. Social Indicators Research, Springer 114(1): 139-152.

Cutler DM and Lleras-Muney A (2006) Education and health: evaluating theories and evidence. National bureau of economic research. 
Datt G (2018) Distribution-sensitive multidimensional poverty measures. The World Bank.

Davies C, Coleman J and Livingstone S (2015) Digital technologies in the lives of young people. Routledge.

Decerf B, Van den Bosch K and Goedemé T (2017) A new measure of income poverty for Europe. Université catholique de Louvain, Center for Operations Research and Econometrics (CORE).

Desmond M (2012) Eviction and the reproduction of urban poverty. American Journal of Sociology, University of Chicago Press Chicago, IL 118(1): 88-133.

Development O for EC and (2010) Sickness, Disability and Work: Breaking the Barriers: A Synthesis of Findings across OECD Countries. OECD Publishing.

Doyal L and Gough I (1984) A theory of human needs. Critical Social Policy 4(10): 638. Available from: http://csp.sagepub.com/cgi/doi/10.1177/026101838400401002 (accessed 20 October 2014).

Francis SK (1992) Effect of Perceived Clothing Deprivation on High School Students' Social Participation. Clothing and Textiles Research Journal, SAGE Publications Inc 10(2): 29-33. Available from: http://dx.doi.org/10.1177/0887302X9201000205.

Gábos A and Goedemé T (2016) The Europe 2020 social inclusion indicators: main conclusions of the ImPRovE project on validity, methodological robustness and interrelationships. Herman Deleeck Centre for Social Policy, University of Antwerp.

Goedeme T, Penne T, Hufkens T, et al. (2017) What Does It Mean To Live on the Poverty Threshold? Lessons From Reference Budgets.

Goedemé T and Rottiers S (2011) Poverty in the enlarged European Union. A 
discussion about definitions and reference groups. Sociology Compass, Wiley Online Library 5(1): 77-91.

Gordon D, Pantazis C and Townsend P (2000) Absolute and overall poverty: a European history and proposal for measurement. In: Gordon D and Townsend P (eds), Breadline Europe: The Measurement of Poverty, pp. 79-105.

Guio A-C, Marlier E, Gordon D, et al. (2016) Improving the measurement of material deprivation at the European Union level. Journal of European Social Policy 26(3): 219-333.

Gundersen C and Ribar D (2011) Food insecurity and insufficiency at low levels of food expenditures. Review of Income and Wealth, Wiley Online Library 57(4): 704-726.

Gundersen C and Ziliak JP (2015) Food insecurity and health outcomes. Health affairs, Health Affairs 34(11): 1830-1839.

Halleröd B (2006a) Sour Grapes: Relative Deprivation, Adaptive Preferences and the Measurement of Poverty. Journal of Social Policy 35(03): 371. Available from: http://www.journals.cambridge.org/abstract_S0047279406009834.

Halleröd B (2006b) Sour Grapes: Relative Deprivation, Adaptive Preferences and the Measurement of Poverty. Journal of Social Policy 35(03): 371. Available from: http://www.journals.cambridge.org/abstract_S0047279406009834 (accessed 20 October 2014).

Hästbacka E, Nygård M and Nyqvist F (2016) Barriers and facilitators to societal participation of people with disabilities: A scoping review of studies concerning European countries. ALTER-European Journal of Disability Research, Elsevier 10(3): 201-220. 
Hauser RM and Warren JR (1997) 4. Socioeconomic Indexes for Occupations: A Review, Update, and Critique. Sociological methodology, SAGE Publications Sage CA: Los Angeles, CA 27(1): 177-298.

Helliwell JF and Putnam RD (2007) Education and social capital. Eastern Economic Journal, Springer 33(1): 1-19.

Hick R (2013) Poverty, Preference or Pensioners? Measuring Material Deprivation in the UK*. Fiscal Studies, Blackwell Publishing Ltd 34(1): 31-54. Available from: http://dx.doi.org/10.1111/j.1475-5890.2013.00176.x.

Hick R (2014) On 'consistent'poverty. Social indicators research 118(3): 1087-1102.

Hildebrand VA, Alperin P, Noel M, et al. (2017) Measuring and accounting for the deprivation gap of Portuguese immigrants in Luxembourg. Review of Income and Wealth, Wiley Online Library 63(2): 288-309.

Jyoti DF, Frongillo EA and Jones SJ (2005) Food insecurity affects school children's academic performance, weight gain, and social skills. The Journal of nutrition, Am Soc Nutrition 135(12): 2831-2839.

Kautz T, Heckman JJ, Diris R, et al. (2014) Fostering and measuring skills: Improving cognitive and non-cognitive skills to promote lifetime success. National Bureau of Economic Research.

Kis AB, Özdemir E and Ward T (2015) Micro and Macro Drivers of Material Deprivation Rates.

Kuhn P and Mansour H (2014) Is Internet job search still ineffective? The Economic Journal, Wiley Online Library 124(581): 1213-1233.

Lansley S and Mack J (2015) Breadline Britain : the rise of mass poverty. London: 
Oneworld.

Lelkes O, \& Gasior K (2018) Income Poverty in the EU: What Do We Actually Measure? Empirical Evidence on Choices, Underlying Assumptions and Implications (Based on EU-SILC 2005-2014). In Reducing Inequalities (pp. 75-95). Palgrave Macmillan, Cham.

Lister R (1990) The exclusive society citizenship and the poor. Child poverty action Group.

Lister R (2004) Poverty: key concepts. Cambridge: Polity.

Loopstra R and Tarasuk V (2012) The Relationship between Food Banks and Household Food Insecurity among Low-Income Toronto Families. Canadian Public Policy / Analyse de Politiques, [University of Toronto Press, Canadian Public Policy] 38(4): 497-514. Available from: http://www.jstor.org/stable/41756766.

Loopstra R, Reeves A and Stuckler D (2015) Rising food insecurity in Europe. The Lancet, Elsevier 385(9982): 2041.

Loopstra R, Reeves A, McKee M, et al. (2016) Food insecurity and social protection in Europe: quasi-natural experiment of Europe's great recessions 2004-2012. Preventive medicine, Academic Press 89: 44-50.

Mack J and Lansley S (1985) Poor Britain. G. Allen \& Unwin.

Maître B, Nolan B and Whelan C (2013) GINI DP 79: A Critical Evaluation of the EU 2020 Poverty and Social Exclusion Target: An Analysis of EU-SILC 2009. AIAS, Amsterdam Institute for Advanced Labour Studies.

McKay S (2004) Poverty or preference: what do 'consensual deprivation indicators' really mean? Fiscal Studies, The Institute for Fiscal Studies 25(2): 201-223. 
Available from: http://dx.doi.org/10.1111/j.1475-5890.2004.tb00102.x.

McKnight A (2013) Measuring material deprivation over the economic crisis: does a reevaluation of 'need'affect measures of material deprivation. GINI policy paper.

Meyer BD and Mittag N (2015) Using Linked Survey and Administrative Data to Better Measure Income: Implications for Poverty, Program Effectiveness and Holes in the Safety Net. National Bureau of Economic Research Working Paper Series No. 21676. Available from: http://www.nber.org/papers/w21676.

Meyer BD, Mok WKC and Sullivan JX (2009) The Under-Reporting of Transfers in Household Surveys: Its Nature and Consequences. National Bureau of Economic Research Working Paper Series No. 15181. Available from: http://www.nber.org/papers/w15181.

Middlemiss L and Gillard R (2015) Fuel poverty from the bottom-up: Characterising household energy vulnerability through the lived experience of the fuel poor. Energy Research \& Social Science 6: 146-154. Available from: http://www.sciencedirect.com/science/article/pii/S2214629615000213. Mood C and Jonsson JO (2016) The social consequences of poverty: an empirical test on longitudinal data. Social indicators research, Springer 127(2): 633-652.

Nolan B and Whelan CT (2007) On the multidimensionality of poverty and social exclusion. Inequality and poverty re-examined (Part II): 146-165.

Nolan B and Whelan CT (2011) Poverty and deprivation in Europe. OUP Catalogue, Oxford University Press.

OECD (2016) Health at a glance : Europe 2016 : state of health in the EU cycle. Health at a glance, 2016, Paris: Paris: OECD Publishing. 
Passias EJ, Sayer L and Pepin JR (2017) Who Experiences Leisure Deficits? Mothers' Marital Status and Leisure Time. Journal of Marriage and Family, Wiley Subscription Services, Inc. 79(4): 1001-1022. Available from: http://dx.doi.org/10.1111/jomf.12365.

Penne T, Parcerisas IC, Mäkinen L, et al. (2016) Can reference budgets be used as a poverty line. ImPRovE WP (16/05).

Pryor L, Lioret S, van der Waerden J, et al. (2016) Food insecurity and mental health problems among a community sample of young adults. Social Psychiatry and Psychiatric Epidemiology 51(8): 1073-1081. Available from: http://dx.doi.org/10.1007/s00127-016-1249-9.

Putnam RD (2001) Bowling alone: The collapse and revival of American community. Simon and Schuster.

Ravallion M (1996) Issues in measuring and modeling poverty. World Bank Policy Research Working Paper. Available from: https://ssrn.com/abstract=636124. Sen A (1983) Poor, relatively speaking. Oxford economic papers, JSTOR 35(2): 153169.

Short K (2011) The research supplemental poverty measure: 2010. Current Population Reports. Available from: http://www.census.gov/prod/2011pubs/p60-241.

Siminski P and Yerokhin O (2012) Is the Age Gradient in Self Reported Material Hardship Explained By Resources, Needs, Behaviors, or Reporting Bias? Review of Income and Wealth, Wiley Online Library 58(4): 715-741.

Smith KP and Christakis NA (2008) Social networks and health. Annu. Rev. Sociol, Annual Reviews 34: 405-429. 
Thomson H and Thomas S (2015) Developing empirically supported theories of change for housing investment and health. Social Science \& Medicine 124: 205-214. Available from:

http://www.sciencedirect.com/science/article/pii/S0277953614007758.

Townsend P (1962) The meaning of poverty. The British Journal of Sociology, JSTOR 13(3): 210-227.

Townsend P (1979) Poverty in the United Kingdom : a survey of household resources and standards of living. University of California Press.

Townsend P (1987) Deprivation. Journal of Social Policy 16(02): 125.

Townsend P (1993) The international analysis of poverty. Harvester Wheatsheaf.

Tunstall R, Bevan M, Bradshaw J, et al. (2013) The links between housing and poverty: an evidence review. JRF Report, York: Joseph Rowntree Foundation.

Turner-Bowker DM (2001) How Can You Pull Yourself up by Your Bootstraps, if You Don't Have Boots? Work-Appropriate Clothing for Poor Women. Journal of Social Issues, Blackwell Publishers Inc. 57(2): 311-322. Available from: http://dx.doi.org/10.1111/0022-4537.00215.

Van Ingen E and Van Eijck K (2009) Leisure and Social Capital: An Analysis of Types of Company and Activities. Leisure Sciences, Routledge 31(2): 192-206. Available from: http://dx.doi.org/10.1080/01490400802686078.

van Rijn RM, Robroek SJW, Brouwer S, et al. (2014) Influence of poor health on exit from paid employment: a systematic review. Occupational and Environmental Medicine 71(4): 295 LP - 301. Available from: http://oem.bmj.com/content/71/4/295.abstract. 
Whelan CT and Maître B (2012) Understanding material deprivation: A comparative European analysis. Research in Social Stratification and Mobility 30(4): 489-503. 


\section{Appendix}


Table A1: Adult, household and child deprivation indicators

\begin{tabular}{|c|c|c|c|c|}
\hline $\begin{array}{l}\text { Adult } \\
\text { indicators }\end{array}$ & Description & Unit & Mode of collection & $\begin{array}{l}\text { Enforced } \\
\text { criterion }\end{array}$ \\
\hline Acloth & Replace worn-out clothes by some new (not second-hand) ones & All adult $(16+) \mathrm{HH}$ members & Personal or $\mathrm{HH}$ resp. & $\checkmark$ \\
\hline Ashoes & Two pairs of properly fitting shoes (including a pair of all-weather shoes) & All adult (16+) HH members & Personal or $\mathrm{HH}$ resp. & $\checkmark$ \\
\hline Ameet & Meeting friends/family for a drink/meal at least once a month & All adult (16+) HH members & Personal or HH resp. & $\checkmark$ \\
\hline Aleisure & Regulary participate in a leisure activity e.g. sport, cinema, concert & All adult $(16+) \mathrm{HH}$ members & Personal or HH resp. & $\checkmark$ \\
\hline Asmoney & Spend a small amount of money each week on yourself & All adult $(16+) \mathrm{HH}$ members & Personal or HH resp. & $\checkmark$ \\
\hline Aunmet & Unmet need for medical examination or treatment & Selected resp. or all adult(16+) & Personal or $\mathrm{HH}$ resp. & $\checkmark$ \\
\hline Adentist & Unmet need for dental examination or treatment & Selected resp. or all adult(16+) & Personal or HH resp. & $\checkmark$ \\
\hline $\begin{array}{l}\text { Household } \\
\text { indicators }\end{array}$ & Description & Unit & Mode of collection & $\begin{array}{l}\text { Enforced } \\
\text { criterion }\end{array}$ \\
\hline Hmeat & A meal with meat, chicken or fish (or vegetarian equiv.) at least once a day & Household & Household respondent & $\checkmark$ \\
\hline Hwarm & Ability to keep home adequately warm & Household & Household respondent & $\checkmark$ \\
\hline Hholiday & One week annual holiday away from home & Household & Household respondent & $\checkmark$ \\
\hline Hunexp & $\begin{array}{l}\text { Ability to face unexpected financial expenses (e.g. surgery, funeral, major } \\
\text { repair in the house, replacement of durables, car etc.) }\end{array}$ & Household & Household respondent & $\checkmark$ \\
\hline Hrefurnish & Replace worn-out furniture & Household & Household respondent & $\checkmark$ \\
\hline Hnet & Internet connection & Household & Household respondent & $\checkmark$ \\
\hline HPC & Computer & Household & Household respondent & $\checkmark$ \\
\hline Hcar & Car & Household & Household respondent & $\checkmark$ \\
\hline Hmortgage & Arrears on mortgage or rent payments & Household & Household respondent & $\checkmark$ \\
\hline Hutility & Arrears on utility bills & Household & Household respondent & $\checkmark$ \\
\hline Hloan & Arrears on hire purchase instalments or loan payments & Household & Household respondent & $\checkmark$ \\
\hline Hroof & $\begin{array}{l}\text { Leaking roof, damps walls/floors/foundation, or rot in window frames or } \\
\text { floor }\end{array}$ & Household & Household respondent & $\mathrm{X}$ \\
\hline Hspace & Shortage of space in dwelling (subj.) & Household & Household respondent & $\mathrm{X}$ \\
\hline Hhoc & A heavy or slight financial burden of the total housing cost & Household & Household respondent & $\mathrm{X}$ \\
\hline Hevict & $\begin{array}{l}\text { Forced to leave dwelling due to eviction or distraint or for financial } \\
\text { difficulties }\end{array}$ & Household & Household respondent & $\checkmark$ \\
\hline
\end{tabular}




\begin{tabular}{|l|l|c|c|}
\hline Hnoise & Noise from neighbors or from street & Household \\
\hline Hpollution & Pollution, grime or other environmental problems in the local neighborhood & Household \\
\hline Hcrime & Crime, violence and vandalism in the area & Household & Household respondent \\
\hline Hlitter & Litter lying around the neighborhood & Household & Household respondent \\
\hline Hdamaged & Damaged public amenities in the neighborhood & Household & Household respondent \\
\hline
\end{tabular}

\begin{tabular}{|c|c|c|c|c|}
\hline $\begin{array}{l}\text { Child } \\
\text { indicators }\end{array}$ & Description & Unit & Mode of collection & $\begin{array}{l}\text { Enforced } \\
\text { criterion }\end{array}$ \\
\hline CHcloth & Some new (not second-hand) ones & Child aged 1-16 & Household respondent & $\checkmark$ \\
\hline CHshoes & Two pairs of properly fitting shoes (including a pair of all-weather shoes) & Child aged 1-16 & Household respondent & $\checkmark$ \\
\hline CHfruit & Fresh fruit and vegetables once a day & Child aged 1-16 & Household respondent & $\checkmark$ \\
\hline CHthmeals & Three meals a day & Child aged 1-16 & Household respondent & $\checkmark$ \\
\hline CHmeat & $\begin{array}{l}\text { One meal with meat, chicken or fish (or vegetarian equivalent) at least once a } \\
\text { day }\end{array}$ & Child aged 1-16 & Household respondent & $\checkmark$ \\
\hline CHbooks & Books at home suitable for their age & Child aged 1-16 & Household respondent & $\checkmark$ \\
\hline CHtoys & Outdoor leisure equipment (bicycle, roller skates, etc.) & Child aged 1-16 & Household respondent & $\checkmark$ \\
\hline CHgames & $\begin{array}{l}\text { Indoor games (eucational baby toys, building blocks, board games, PC games } \\
\text { etc.) }\end{array}$ & Child aged 1-16 & Household respondent & $\checkmark$ \\
\hline CHleisure & Regular leisure activity (swimming, playing an instrument, riding a bicycle etc.) & Child aged 1-16 & Household respondent & $\checkmark$ \\
\hline CHceleb & Celebrations on special occasions (birthdays, name days, religious events, etc.) & Child aged 1-16 & Household respondent & $\checkmark$ \\
\hline CHmeet & Invite friends round to play and eat from time to time & Child aged 1-16 & Household respondent & $\checkmark$ \\
\hline CHtrips & Participate in school trips and school events that cost money & Child aged 1-16 & Household respondent & $\checkmark$ \\
\hline CHworkspace & Suitable place to study or do homework & Child aged 1-16 & Household respondent & $x$ \\
\hline CHoutplay & Outdoor space in the neighborhood where children can play safely & Child aged 1-16 & Household respondent & $x$ \\
\hline CHholiday & One week annual holiday away from home & Child aged 1-16 & Household respondent & $\checkmark$ \\
\hline CHunmet & Unmet need for medical examination or treatment & Child aged 1-16 & Household respondent & $\checkmark$ \\
\hline CHdentist & Unmet need for dental examination or treatment & Child aged 1-16 & Household respondent & $\checkmark$ \\
\hline
\end{tabular}


Table A2: Missing data and descriptives for total individual sample

\begin{tabular}{|c|c|c|c|c|c|c|c|}
\hline Variable & \# of missing & Total sample & $\%$ of missing & Mean & $\mathrm{Sd}$ & Min & Max \\
\hline Hcloth & 606 & 525,154 & 0.10 & 0.15 & 0.35 & 0 & 1 \\
\hline Hshoes & 589 & 525,154 & 0.10 & 0.04 & 0.20 & 0 & 1 \\
\hline Hmeet & 612 & 525,154 & 0.10 & 0.16 & 0.37 & 0 & 1 \\
\hline Hleisure & 572 & 525,154 & 0.10 & 0.22 & 0.41 & 0 & 1 \\
\hline Hsmoney & 682 & 525,154 & 0.10 & 0.22 & 0.41 & 0 & 1 \\
\hline Hunmet & 531 & 525,154 & 0.10 & 0.03 & 0.18 & 0 & 1 \\
\hline Hdentist & 481 & 525,154 & 0.10 & 0.07 & 0.25 & 0 & 1 \\
\hline CHcloth & 1,169 & 525,154 & 0.20 & 0.03 & 0.17 & 0 & 1 \\
\hline CHshoes & 1,161 & 525,154 & 0.20 & 0.02 & 0.13 & 0 & 1 \\
\hline CHfruit & 1,172 & 525,154 & 0.20 & 0.02 & 0.14 & 0 & 1 \\
\hline CHthmeals & 1,159 & 525,154 & 0.20 & 0.00 & 0.07 & 0 & 1 \\
\hline CHmeat & 1,151 & 525,154 & 0.20 & 0.02 & 0.14 & 0 & 1 \\
\hline CHbooks & 1,215 & 525,154 & 0.20 & 0.02 & 0.15 & 0 & 1 \\
\hline CHtoys & 1,149 & 525,154 & 0.20 & 0.03 & 0.17 & 0 & 1 \\
\hline CHgames & 1,465 & 525,154 & 0.30 & 0.02 & 0.15 & 0 & 1 \\
\hline CHleisure & 1,886 & 525,154 & 0.40 & 0.05 & 0.21 & 0 & 1 \\
\hline CHceleb & 1,418 & 525,154 & 0.30 & 0.02 & 0.16 & 0 & 1 \\
\hline CHmeet & 1,680 & 525,154 & 0.30 & 0.03 & 0.17 & 0 & 1 \\
\hline CHtrips & 1,125 & 525,154 & 0.20 & 0.03 & 0.16 & 0 & 1 \\
\hline CHworkspace & 1,421 & 525,154 & 0.30 & 0.02 & 0.15 & 0 & 1 \\
\hline CHholiday & 2,111 & 525,154 & 0.40 & 0.07 & 0.26 & 0 & 1 \\
\hline CHunmet & 11 & 525,154 & 0.00 & 0.00 & 0.07 & 0 & 1 \\
\hline CHdentist & 54 & 525,154 & 0.00 & 0.01 & 0.08 & 0 & 1 \\
\hline Hmeat & 191 & 525,154 & 0.00 & 0.11 & 0.31 & 0 & 1 \\
\hline Hwarm & 245 & 525,154 & 0.00 & 0.10 & 0.30 & 0 & 1 \\
\hline Hholiday & 383 & 525,154 & 0.10 & 0.40 & 0.49 & 0 & 1 \\
\hline Hunexp & 683 & 525,154 & 0.10 & 0.37 & 0.48 & 0 & 1 \\
\hline Hrefurnish & 596 & 525,154 & 0.10 & 0.32 & 0.47 & 0 & 1 \\
\hline Hnet & 200 & 525,154 & 0.00 & 0.09 & 0.29 & 0 & 1 \\
\hline HPC & 400 & 525,154 & 0.10 & 0.17 & 0.38 & 0 & 1 \\
\hline Hcar & 198 & 525,154 & 0.00 & 0.07 & 0.26 & 0 & 1 \\
\hline Hmortgage & 423 & 525,154 & 0.10 & 0.03 & 0.18 & 0 & 1 \\
\hline Hutility & 363 & 525,154 & 0.10 & 0.10 & 0.30 & 0 & 1 \\
\hline Hloan & 345 & 525,154 & 0.10 & 0.04 & 0.19 & 0 & 1 \\
\hline Hroof & 168 & 525,154 & 0.00 & 0.00 & 0.06 & 0 & 1 \\
\hline Hspace & 210 & 525,154 & 0.00 & 0.12 & 0.33 & 0 & 1 \\
\hline Hhoc & 721 & 525,154 & 0.10 & 0.83 & 0.38 & 0 & 1 \\
\hline Hevict & 1,058 & 525,154 & 0.20 & 0.02 & 0.13 & 0 & 1 \\
\hline Total missing & 8703 & 525,154 & 1.70 & & & & \\
\hline
\end{tabular}

Notes: The adult items are distributed to household members; if an adult is deprived, the whole household is taken as deprived. 
Table A3: Missing data for deprivation indicators for each country

\begin{tabular}{|c|c|c|c|}
\hline Country & \# of missing & Total sample & $\%$ of missing \\
\hline AT & 295 & 13,610 & 2.20 \\
\hline BE & 455 & 14,721 & 3.10 \\
\hline$B G$ & 23 & 15,047 & 0.20 \\
\hline $\mathrm{CY}$ & 0 & 9,283 & 0.00 \\
\hline$C Z$ & 7 & 23,302 & 0.00 \\
\hline DE & 1,298 & 28,368 & 4.60 \\
\hline DK & 703 & 15,025 & 4.70 \\
\hline EE & 322 & 13,542 & 2.40 \\
\hline EL & 0 & 18,035 & 0.00 \\
\hline ES & 524 & 36,865 & 1.40 \\
\hline $\mathrm{FI}$ & 607 & 25,157 & 2.40 \\
\hline $\mathrm{FR}$ & 939 & 25,611 & 3.70 \\
\hline $\mathrm{HU}$ & 557 & 25,053 & 2.20 \\
\hline $\mathrm{IE}$ & 443 & 12,641 & 3.50 \\
\hline IT & 0 & 51,196 & 0.00 \\
\hline LT & 12 & 12,852 & 0.10 \\
\hline LU & 459 & 11,406 & 4.00 \\
\hline LV & 10 & 14,403 & 0.10 \\
\hline NL & 616 & 23,687 & 2.60 \\
\hline PL & 5 & 38,541 & 0.00 \\
\hline PT & 335 & 13,013 & 2.60 \\
\hline RO & 0 & 18,703 & 0.00 \\
\hline SI & 35 & 29,576 & 0.10 \\
\hline SK & 268 & 16,137 & 1.70 \\
\hline UK & 790 & 19,380 & 4.10 \\
\hline Total & 8,703 & 525,154 & 1.70 \\
\hline SE & 8,387 & 18,441 & 45.50 \\
\hline
\end{tabular}


Table A4: Testing construct validity of each scale - percentages among those identified by each measure reporting some difficulties making ends meet, having income below $120 \%$ of median and reporting at least one financial strain

\begin{tabular}{lccc}
\hline Components & $\begin{array}{c}\text { At least some } \\
\text { difficulties } \\
\text { making ends meet }\end{array}$ & $\begin{array}{c}\text { Having income } \\
\text { below 120\% of median }\end{array}$ & $\begin{array}{c}\text { Reporting at least one } \\
\text { financial strain }\end{array}$ \\
\hline Food & 95 & 89 & 93 \\
Clothing & 97 & 88 & 100 \\
Habitancy & 94 & 82 & 95 \\
Fuel & 95 & 86 & 92 \\
Housing facilities & 91 & 83 & 87 \\
Health care & 95 & 83 & 91 \\
Harmful environment & 79 & 70 & 76 \\
Education goods & 90 & 90 & 89 \\
Learning goods & 98 & 92 & 93 \\
Information goods & 94 & 89 & 83 \\
Leisure activities & 88 & 81 & 89 \\
Social activities & 92 & 84 & \\
\end{tabular}


Table A5: Rates for each scale for each country

\begin{tabular}{|c|c|c|c|c|c|c|c|c|c|c|c|c|}
\hline Country & Food & Clothing & Habitancy & Fuel & $\begin{array}{l}\text { Housing } \\
\text { facilities }\end{array}$ & $\begin{array}{l}\text { Health } \\
\text { care }\end{array}$ & $\begin{array}{c}\text { Harmful } \\
\text { environment }\end{array}$ & $\begin{array}{l}\text { Education } \\
\text { goods }\end{array}$ & $\begin{array}{l}\text { Learning } \\
\text { goods }\end{array}$ & $\begin{array}{l}\text { Information } \\
\text { goods }\end{array}$ & $\begin{array}{l}\text { Leisure } \\
\text { activities }\end{array}$ & $\begin{array}{c}\text { Social } \\
\text { activities }\end{array}$ \\
\hline AT & 0.10 & 0.09 & 0.02 & 0.07 & 0.10 & 0.01 & 0.03 & 0.02 & 0.01 & 0.05 & 0.34 & 0.10 \\
\hline $\mathrm{BE}$ & 0.05 & 0.08 & 0.02 & 0.09 & 0.09 & 0.02 & 0.05 & 0.03 & 0.02 & 0.06 & 0.31 & 0.12 \\
\hline$B G$ & 0.42 & 0.68 & 0.03 & 0.70 & 0.37 & 0.26 & 0.13 & 0.12 & 0.18 & 0.26 & 0.81 & 0.60 \\
\hline$C Y$ & 0.05 & 0.12 & 0.04 & 0.30 & 0.29 & 0.13 & 0.04 & 0.03 & 0.02 & 0.06 & 0.49 & 0.08 \\
\hline $\mathrm{CZ}$ & 0.11 & 0.09 & 0.03 & 0.08 & 0.15 & 0.01 & 0.08 & 0.02 & 0.02 & 0.08 & 0.44 & 0.05 \\
\hline $\mathrm{DE}$ & 0.10 & 0.10 & 0.02 & 0.08 & 0.10 & 0.05 & 0.04 & 0.03 & 0.01 & 0.07 & 0.35 & 0.27 \\
\hline DK & 0.01 & 0.06 & 0.01 & 0.04 & 0.05 & 0.02 & 0.01 & 0.01 & 0.01 & 0.02 & 0.13 & 0.02 \\
\hline EE & 0.10 & 0.13 & 0.01 & 0.11 & 0.21 & 0.08 & 0.02 & 0.03 & 0.03 & 0.07 & 0.54 & 0.12 \\
\hline EL & 0.09 & 0.13 & 0.04 & 0.27 & 0.24 & 0.14 & 0.07 & 0.06 & 0.04 & 0.14 & 0.53 & 0.11 \\
\hline ES & 0.02 & 0.05 & 0.05 & 0.10 & 0.15 & 0.07 & 0.03 & 0.02 & 0.01 & 0.11 & 0.42 & 0.10 \\
\hline $\mathrm{FI}$ & 0.03 & 0.07 & 0.03 & 0.08 & 0.04 & 0.01 & 0.01 & 0.01 & 0.00 & 0.03 & 0.16 & 0.02 \\
\hline FR & 0.08 & 0.12 & 0.04 & 0.11 & 0.12 & 0.08 & 0.03 & 0.03 & 0.01 & 0.06 & 0.36 & 0.08 \\
\hline $\mathrm{HU}$ & 0.29 & 0.35 & 0.03 & 0.25 & 0.19 & 0.07 & 0.06 & 0.03 & 0.08 & 0.15 & 0.73 & 0.42 \\
\hline $\mathrm{IE}$ & 0.03 & 0.06 & 0.05 & 0.13 & 0.09 & 0.06 & 0.04 & 0.02 & 0.01 & 0.08 & 0.44 & 0.10 \\
\hline IT & 0.07 & 0.11 & 0.03 & 0.18 & 0.07 & 0.14 & 0.06 & 0.05 & 0.03 & 0.05 & 0.50 & 0.14 \\
\hline LT & 0.21 & 0.29 & 0.01 & 0.29 & 0.24 & 0.06 & 0.05 & 0.04 & 0.05 & 0.12 & 0.65 & 0.32 \\
\hline LU & 0.02 & 0.06 & 0.02 & 0.02 & 0.12 & 0.01 & 0.02 & 0.05 & 0.01 & 0.02 & 0.18 & 0.06 \\
\hline LV & 0.24 & 0.41 & 0.04 & 0.28 & 0.33 & 0.25 & 0.08 & 0.04 & 0.09 & 0.10 & 0.76 & 0.32 \\
\hline NL & 0.02 & 0.03 & 0.01 & 0.03 & 0.09 & 0.01 & 0.05 & 0.02 & 0.00 & 0.01 & 0.17 & 0.02 \\
\hline PL & 0.19 & 0.20 & 0.01 & 0.25 & 0.21 & 0.11 & 0.04 & 0.05 & 0.06 & 0.15 & 0.68 & 0.20 \\
\hline PT & 0.05 & 0.25 & 0.04 & 0.30 & 0.22 & 0.22 & 0.06 & 0.08 & 0.07 & 0.14 & 0.67 & 0.28 \\
\hline RO & 0.30 & 0.47 & 0.01 & 0.37 & 0.33 & 0.27 & 0.07 & 0.23 & 0.29 & 0.28 & 0.87 & 0.68 \\
\hline SI & 0.11 & 0.15 & 0.02 & 0.20 & 0.21 & 0.00 & 0.03 & 0.02 & 0.01 & 0.05 & 0.37 & 0.07 \\
\hline SK & 0.25 & 0.17 & 0.04 & 0.14 & 0.11 & 0.03 & 0.10 & 0.04 & 0.05 & 0.13 & 0.61 & 0.15 \\
\hline UK & 0.04 & 0.08 & 0.02 & 0.08 & 0.10 & 0.01 & 0.07 & 0.02 & 0.01 & 0.04 & 0.36 & 0.12 \\
\hline Total & 0.10 & 0.14 & 0.03 & 0.15 & 0.14 & 0.08 & 0.05 & 0.04 & 0.04 & 0.09 & 0.45 & 0.18 \\
\hline
\end{tabular}


Table A6: Rates of each scale for each country after adjustment

\begin{tabular}{|c|c|c|c|c|c|c|c|c|c|c|c|c|}
\hline Country & Food & Clothing & Habitancy & Fuel & $\begin{array}{l}\text { Housing } \\
\text { facilities }\end{array}$ & $\begin{array}{l}\text { Health } \\
\text { care }\end{array}$ & $\begin{array}{c}\text { Harmful } \\
\text { environment }\end{array}$ & $\begin{array}{l}\text { Education } \\
\text { goods }\end{array}$ & $\begin{array}{l}\text { Learning } \\
\text { goods }\end{array}$ & $\begin{array}{l}\text { Information } \\
\text { goods }\end{array}$ & $\begin{array}{l}\text { Leisure } \\
\text { activities }\end{array}$ & $\begin{array}{c}\text { Social } \\
\text { activities }\end{array}$ \\
\hline AT & 0.06 & 0.05 & 0.02 & 0.04 & 0.05 & 0.01 & 0.01 & 0.01 & 0.01 & 0.03 & 0.14 & 0.06 \\
\hline $\mathrm{BE}$ & 0.04 & 0.07 & 0.02 & 0.07 & 0.06 & 0.02 & 0.02 & 0.02 & 0.02 & 0.04 & 0.17 & 0.08 \\
\hline$B G$ & 0.35 & 0.44 & 0.03 & 0.45 & 0.24 & 0.19 & 0.08 & 0.09 & 0.14 & 0.19 & 0.49 & 0.39 \\
\hline$C Y$ & 0.04 & 0.09 & 0.04 & 0.24 & 0.22 & 0.12 & 0.02 & 0.03 & 0.02 & 0.05 & 0.36 & 0.07 \\
\hline $\mathrm{CZ}$ & 0.06 & 0.06 & 0.03 & 0.05 & 0.06 & 0.01 & 0.02 & 0.02 & 0.02 & 0.05 & 0.17 & 0.03 \\
\hline $\mathrm{DE}$ & 0.06 & 0.06 & 0.01 & 0.05 & 0.06 & 0.03 & 0.02 & 0.01 & 0.01 & 0.04 & 0.16 & 0.12 \\
\hline DK & 0.01 & 0.03 & 0.01 & 0.02 & 0.02 & 0.02 & 0.01 & 0.01 & 0.01 & 0.01 & 0.06 & 0.01 \\
\hline EE & 0.07 & 0.09 & 0.01 & 0.08 & 0.10 & 0.05 & 0.01 & 0.01 & 0.02 & 0.04 & 0.24 & 0.07 \\
\hline EL & 0.07 & 0.10 & 0.04 & 0.20 & 0.16 & 0.10 & 0.03 & 0.04 & 0.03 & 0.09 & 0.30 & 0.09 \\
\hline ES & 0.01 & 0.04 & 0.05 & 0.08 & 0.10 & 0.05 & 0.02 & 0.02 & 0.01 & 0.08 & 0.26 & 0.08 \\
\hline $\mathrm{FI}$ & 0.02 & 0.04 & 0.02 & 0.05 & 0.02 & 0.00 & 0.00 & 0.00 & 0.00 & 0.02 & 0.09 & 0.01 \\
\hline FR & 0.06 & 0.08 & 0.04 & 0.09 & 0.07 & 0.04 & 0.02 & 0.02 & 0.01 & 0.04 & 0.18 & 0.06 \\
\hline $\mathrm{HU}$ & 0.21 & 0.25 & 0.03 & 0.21 & 0.14 & 0.06 & 0.04 & 0.03 & 0.07 & 0.11 & 0.40 & 0.28 \\
\hline $\mathrm{IE}$ & 0.02 & 0.05 & 0.05 & 0.10 & 0.06 & 0.03 & 0.02 & 0.02 & 0.01 & 0.06 & 0.25 & 0.08 \\
\hline IT & 0.06 & 0.09 & 0.03 & 0.15 & 0.05 & 0.10 & 0.03 & 0.04 & 0.03 & 0.04 & 0.29 & 0.10 \\
\hline LT & 0.14 & 0.19 & 0.01 & 0.17 & 0.14 & 0.04 & 0.02 & 0.03 & 0.04 & 0.09 & 0.32 & 0.20 \\
\hline LU & 0.01 & 0.05 & 0.02 & 0.02 & 0.07 & 0.01 & 0.01 & 0.02 & 0.01 & 0.01 & 0.11 & 0.05 \\
\hline LV & 0.20 & 0.29 & 0.04 & 0.23 & 0.20 & 0.19 & 0.05 & 0.04 & 0.08 & 0.08 & 0.43 & 0.23 \\
\hline NL & 0.01 & 0.02 & 0.01 & 0.02 & 0.04 & 0.01 & 0.01 & 0.01 & 0.00 & 0.01 & 0.07 & 0.02 \\
\hline PL & 0.13 & 0.14 & 0.01 & 0.17 & 0.13 & 0.07 & 0.02 & 0.04 & 0.05 & 0.09 & 0.32 & 0.14 \\
\hline PT & 0.03 & 0.16 & 0.04 & 0.15 & 0.12 & 0.13 & 0.02 & 0.05 & 0.05 & 0.08 & 0.28 & 0.16 \\
\hline RO & 0.20 & 0.28 & 0.00 & 0.25 & 0.21 & 0.17 & 0.03 & 0.16 & 0.19 & 0.17 & 0.41 & 0.36 \\
\hline SI & 0.08 & 0.11 & 0.02 & 0.14 & 0.13 & 0.00 & 0.02 & 0.01 & 0.00 & 0.03 & 0.22 & 0.05 \\
\hline SK & 0.14 & 0.10 & 0.04 & 0.08 & 0.07 & 0.02 & 0.04 & 0.03 & 0.04 & 0.08 & 0.23 & 0.08 \\
\hline UK & 0.03 & 0.06 & 0.02 & 0.05 & 0.05 & 0.00 & 0.03 & 0.01 & 0.01 & 0.03 & 0.19 & 0.08 \\
\hline Total & 0.07 & 0.09 & 0.02 & 0.11 & 0.08 & 0.05 & 0.02 & 0.03 & 0.03 & 0.06 & 0.23 & 0.11 \\
\hline
\end{tabular}


Table A7: Missing data and descriptives of poverty and validity measures for the whole sample

\begin{tabular}{lccccccc}
\hline & \# of missing & Total sample & \% of missing & mean & sd & min & $\max$ \\
\hline Poverty measures & & & & & & & \\
EU 2020 poverty target & 8,863 & 525,154 & 1.69 & 0.26 & 0.44 & 0 & 1 \\
13 item index (7+ deprived items) & 8,703 & 525,154 & 1.66 & 0.13 & 0.33 & 0 & 1 \\
Income poverty (60\% median) & 0 & 525,154 & 0.00 & 0.16 & 0.36 & 0 & 1 \\
Low work intensity & 160 & 525,154 & 0.03 & 0.06 & 0.24 & 0 & 1 \\
Validity measures & & & & & & & \\
Ability to make ends meet & 440 & 525,154 & 0.08 & 3.20 & 1.30 & 1 & 6 \\
HH income below 120\% median & 0 & 525,154 & 0.00 & 0.65 & 0.48 & 0 & 1 \\
Financial strain index & 2,044 & 525,154 & 0.39 & 1.71 & 1.27 & 0 & 5 \\
Having difficulty making ends meet & 440 & 525,154 & 0.08 & 0.29 & 0.46 & 0 & 1 \\
Inability to pay unexpected expenses & 683 & 525,154 & 0.13 & 0.37 & 0.48 & 0 & 1 \\
Having structural arrears & 631 & 525,154 & 0.12 & 0.12 & 0.33 & 0 & 1 \\
Feeling heavy burden of housing cost & 721 & 525,154 & 0.14 & 0.83 & 0.38 & 0 & 1 \\
Feeling heavy burden of debt & 202 & 525,154 & 0.04 & 0.10 & 0.30 & 0 & 1 \\
\hline Total & 9,162 & 525,154 & 1.74 & & & \\
\hline
\end{tabular}


Table A8: Missing data and descriptives of explanatory variables for household reference person

\begin{tabular}{lccccccc}
\hline & \# of missing & Total sample & \% of missing & mean & sd & min & $\max$ \\
\hline Resources & & & & & & & \\
HRP Social class (ESEC) & 2,722 & 204,169 & 1.33 & 3.04 & 1.71 & 1 & 6 \\
HRP Education (ISCED) & 4,114 & 204,169 & 2.01 & 2.07 & 0.77 & 1 & 3 \\
Unemployed in HH & 0 & 204,169 & 0.00 & 0.10 & 0.31 & 0 & 1 \\
Tenant & 8 & 204,169 & 0.00 & 0.18 & 0.38 & 0 & 1 \\
Needs & & & & & & & \\
Disability in HH & 840 & 204,169 & 0.41 & 0.39 & 0.49 & 0 & 1 \\
Chronic health pr. In HH & 754 & 204,169 & 0.37 & 0.46 & 0.50 & 0 & 1 \\
Self-rated bad health in HH & 627 & 204,169 & 0.31 & 0.19 & 0.39 & 0 & 1 \\
Child aged 0-2 in HH & 0 & 204,169 & 0.00 & 0.07 & 0.26 & 0 & 1 \\
Child aged 3-4 in HH & 0 & 204,169 & 0.00 & 0.05 & 0.21 & 0 & 1 \\
Child aged 5-11 in HH & 0 & 204,169 & 0.00 & 0.14 & 0.35 & 0 & 1 \\
Child aged 12-15 in HH & 0 & 204,169 & 0.00 & 0.11 & 0.31 & 0 & 1 \\
Single parenthood & 66 & 204,169 & 0.03 & 0.04 & 0.19 & 0 & 1 \\
Extended family & 66 & 204,169 & 0.03 & 0.07 & 0.26 & 0 & 1 \\
HRP Divorced / separated & 639 & 204,169 & 0.31 & 0.11 & 0.31 & 0 & 1 \\
HRP female & 0 & 204,169 & 0.00 & 0.40 & 0.49 & 0 & 1 \\
\hline Total & 7,263 & 204,169 & $\% 3.56$ & & & \\
\hline
\end{tabular}


Table A9: Comparing the proposed measure and the EU 2020 poverty target measure without low-work intensity indicator based on identified risk factors relative risk ratios

\begin{tabular}{|c|c|c|c|}
\hline & None & Both & Proposed \\
\hline \multicolumn{4}{|l|}{ Resource indicators } \\
\hline \multicolumn{4}{|c|}{ HRP Social class (ref=Salariat) } \\
\hline Intermediate & $0.830^{\star *}$ & $1.302^{\star \star *}$ & $1.282^{\star *}$ \\
\hline Small self-emp. & $0.291^{* * *}$ & $1.538^{\star * \star}$ & $0.465^{\star \star \star}$ \\
\hline Non-manual labor & $0.654^{\star * \star}$ & $1.702^{\star \star \star}$ & $1.246^{*}$ \\
\hline Manual labor & $0.493^{* * *}$ & $1.666^{* * *}$ & 1.016 \\
\hline Never worked & $0.203^{\star * *}$ & $1.406^{\star \star *}$ & $0.400^{* * *}$ \\
\hline \multicolumn{4}{|c|}{ HRP Education (ref=Third level) } \\
\hline Upper secondary & $0.776^{* * *}$ & $1.216^{* *}$ & 1.128 \\
\hline Low second/Primary/Pre & $0.595^{\star * *}$ & $1.720^{\star * *}$ & 1.117 \\
\hline Unemployed in $\mathrm{HH}$ & $0.463^{* * *}$ & $2.179^{\star * *}$ & 1.098 \\
\hline Tenant & $0.782^{* * *}$ & $2.154^{* * *}$ & $1.739^{* * *}$ \\
\hline \multicolumn{4}{|l|}{ Need indicators } \\
\hline Disability in $\mathrm{HH}$ & 0.955 & $1.351^{* * *}$ & $1.317^{\star \star *}$ \\
\hline Chronic health pr. in $\mathrm{HH}$ & 1.088 & $1.101^{*}$ & $1.205^{\star * *}$ \\
\hline Bad subj. health & $0.836^{* * *}$ & $1.649^{* * *}$ & $1.471^{* * *}$ \\
\hline Child aged $0-2$ in $\mathrm{HH}$ & $0.832^{*}$ & $1.199^{*}$ & 1.085 \\
\hline Child aged 3-4 in $\mathrm{HH}$ & 0.984 & 1.187 & 1.169 \\
\hline Child aged 5-11 in $\mathrm{HH}$ & $0.843^{\star *}$ & $1.151^{*}$ & 1.138 \\
\hline Child aged $12-15$ in $\mathrm{HH}$ & 0.915 & $1.378^{* * *}$ & $1.209^{\star *}$ \\
\hline Single parent household & $0.689^{* * *}$ & $1.466^{* * *}$ & $1.231^{*}$ \\
\hline Extended family & 1.042 & $0.804^{\star \star}$ & 1.045 \\
\hline HRP divorced/separated & $0.747^{\star * *}$ & $1.355^{\star \star *}$ & $1.178^{*}$ \\
\hline HRP Female & $0.807^{\star \star \star}$ & $1.259^{\star \star \star}$ & $1.182^{\star * *}$ \\
\hline \multicolumn{4}{|l|}{ Country $(r e f=A T)$} \\
\hline $\mathrm{BE}$ & $0.796^{\star *}$ & 1.017 & $1.476^{\star \star}$ \\
\hline$B G$ & $0.240^{* * *}$ & $3.207^{\star \star \star}$ & $1.484^{* *}$ \\
\hline CY & 1.116 & $4.301^{* * *}$ & $17.141^{* * *}$ \\
\hline $\mathrm{CZ}$ & $1.614^{* * *}$ & $1.763^{* * *}$ & $4.277^{\star \star *}$ \\
\hline DE & 0.911 & $1.726^{\star \star \star}$ & 0.783 \\
\hline DK & $0.550^{\star * *}$ & $0.276^{\star * \star}$ & $0.233^{* * *}$ \\
\hline EE & 0.866 & $2.721^{* * *}$ & $2.012^{* * *}$ \\
\hline EL & $1.637^{* * *}$ & $3.731^{* * *}$ & $10.101^{* * *}$ \\
\hline ES & 0.999 & $1.403^{* * *}$ & $4.386^{* * *}$ \\
\hline $\mathrm{FI}$ & $0.681^{* * *}$ & $0.553^{\star \star \star}$ & $0.759^{*}$ \\
\hline FR & $1.195^{\star}$ & $1.266^{*}$ & $2.203^{\star \star *}$ \\
\hline $\mathrm{HU}$ & $0.614^{\star \star *}$ & $2.542^{\star \star *}$ & $4.665^{\star \star *}$ \\
\hline $\mathrm{IE}$ & 0.845 & 1.213 & $2.502^{\star * *}$ \\
\hline
\end{tabular}




\begin{tabular}{|c|c|c|c|}
\hline IT & $1.281^{* * *}$ & $2.110^{\star * *}$ & $6.164^{\star * *}$ \\
\hline LT & $0.604^{* * *}$ & $2.943^{\star * *}$ & $2.846^{* * *}$ \\
\hline LU & 1.059 & 0.825 & 0.833 \\
\hline LV & $0.588^{\star \star \star}$ & $4.139^{\star \star \star}$ & $2.856^{\star \star *}$ \\
\hline NL & $0.813^{\star}$ & $0.505^{\star \star \star}$ & $0.531^{* * *}$ \\
\hline$P L$ & 0.977 & $3.471^{* * *}$ & $5.051^{* * *}$ \\
\hline PT & 1.119 & $1.455^{\star *}$ & $1.869^{\star * *}$ \\
\hline RO & $0.249^{\star \star \star *}$ & $2.042^{\star \star \star}$ & 0.855 \\
\hline SI & 1.051 & $2.623^{\star \star \star}$ & $5.725^{\star \star \star}$ \\
\hline SK & 1.183 & $2.343^{* * *}$ & $4.281^{\text {***}}$ \\
\hline UK & $0.556^{\star \star *}$ & 0.868 & 1.094 \\
\hline
\end{tabular}

Notes: The EU poverty measure is calculated using only income poverty and material deprivation measure. 
Supplementary material 


\section{S1. Why is accounting for multidimensionality important?}

To examine the utility of multidimensionality, the total deprivation rate is decomposed into its dimensions, and i) the amount of people captured by only one dimension, ii) the association between dimensions, and iii) the risk profiles of the groups captured by each dimension are examined. In this respect, in Table S1, the correlations between dimensions are shown. In Table S2, the incidence rates for each dimension are presented (as a ratio to the total reference population). In Table S3, the results of four multinomial logit models are presented (details explained below).

The value of accounting for dimensionality can be shown based on three points. First, as shown in Table S1, the correlations between dimensions are reasonably high yet still not perfect. This might show that the dimensions represent different aspects of the same phenomenon of poverty while each still capture a distinct group.

\section{Table S1: Correlations among dimensions}

\begin{tabular}{cccccc}
\hline & Basic & Health & Education & Social & Poor60 \\
Basic & 1.00 & & & & \\
Health & 0.54 & 1.00 & & & \\
Education & 0.64 & 0.43 & 1.00 & & \\
Social & 0.77 & 0.50 & 0.67 & 1.00 & \\
Poor60 & 0.44 & 0.28 & 0.44 & 0.49 & 1 \\
\hline
\end{tabular}

Indeed and secondly, for all countries, a significant amount of people is deprived only in one dimension - again usually highest for social dimension and lowest for health or education dimension. ${ }^{15}$ These people who are deprived in only one

\footnotetext{
${ }^{15}$ The high rate in the dimension of leisure and social activities depends partly on the holiday item - once it is excluded from the social dimension, the amount of captured only by basic goods dimension increases to $7 \%$, by health to $3 \%$, and by education to $2 \%$, while the amount captured only by leisure and social activities dimension decreases to $8 \%$ in average in the EU.
} 
dimension might possibly not be identified in a unidimensional scale where different types of deprivations put together and a non-zero threshold applied. Indeed, as presented in the next section of the Supplementary Material, when compared to other deprivation scales such as the 9-item basic deprivation index of Whelan and Maitre (2012), and the 13 item index of Guio et al. (2016), the proposed multidimensional deprivation measure captures an additional group of people, a significant majority of whom reports difficulties making ends meet, have income below $120 \%$ of median, and report significant financial strain.

Table S2: Deprivation across dimensions in $25 \mathrm{EU}$ countries

\begin{tabular}{ccccc|cccc}
\hline Country & Basic & Health & Education & Social & $\begin{array}{c}\text { Only } \\
\text { basic }\end{array}$ & $\begin{array}{c}\text { Only } \\
\text { health }\end{array}$ & $\begin{array}{c}\text { Only } \\
\text { education }\end{array}$ & $\begin{array}{c}\text { Only } \\
\text { social }\end{array}$ \\
\hline AT & 0.24 & 0.04 & 0.07 & 0.34 & 0.05 & 0.01 & 0.01 & 0.15 \\
BE & 0.20 & 0.07 & 0.09 & 0.32 & 0.03 & 0.02 & 0.01 & 0.13 \\
BG & 0.87 & 0.33 & 0.37 & 0.82 & 0.06 & 0.01 & 0.00 & 0.03 \\
CY & 0.48 & 0.17 & 0.10 & 0.49 & 0.09 & 0.02 & 0.01 & 0.10 \\
CZ & 0.28 & 0.09 & 0.10 & 0.44 & 0.05 & 0.03 & 0.01 & 0.19 \\
DE & 0.23 & 0.08 & 0.10 & 0.39 & 0.03 & 0.01 & 0.01 & 0.17 \\
DK & 0.12 & 0.04 & 0.03 & 0.14 & 0.05 & 0.01 & 0.01 & 0.06 \\
EE & 0.35 & 0.10 & 0.11 & 0.55 & 0.05 & 0.01 & 0.01 & 0.22 \\
EL & 0.44 & 0.19 & 0.18 & 0.53 & 0.05 & 0.03 & 0.02 & 0.12 \\
ES & 0.24 & 0.10 & 0.12 & 0.42 & 0.04 & 0.02 & 0.01 & 0.18 \\
FI & 0.16 & 0.02 & 0.04 & 0.17 & 0.07 & 0.01 & 0.01 & 0.07 \\
FR & 0.26 & 0.10 & 0.08 & 0.37 & 0.05 & 0.02 & 0.01 & 0.14 \\
HU & 0.56 & 0.12 & 0.20 & 0.75 & 0.03 & 0.01 & 0.00 & 0.20 \\
IE & 0.22 & 0.09 & 0.11 & 0.44 & 0.03 & 0.02 & 0.01 & 0.21 \\
IT & 0.26 & 0.18 & 0.10 & 0.50 & 0.03 & 0.03 & 0.01 & 0.21 \\
LT & 0.55 & 0.10 & 0.16 & 0.67 & 0.07 & 0.01 & 0.00 & 0.17 \\
LU & 0.17 & 0.04 & 0.07 & 0.18 & 0.06 & 0.01 & 0.02 & 0.06 \\
LV & 0.64 & 0.30 & 0.18 & 0.76 & 0.05 & 0.01 & 0.00 & 0.16 \\
NL & 0.12 & 0.05 & 0.03 & 0.17 & 0.04 & 0.02 & 0.01 & 0.09 \\
PL & 0.45 & 0.14 & 0.20 & 0.68 & 0.03 & 0.01 & 0.01 & 0.22 \\
PT & 0.47 & 0.25 & 0.20 & 0.67 & 0.03 & 0.02 & 0.00 & 0.17 \\
RO & 0.70 & 0.31 & 0.46 & 0.88 & 0.01 & 0.01 & 0.00 & 0.13 \\
SI & 0.39 & 0.04 & 0.07 & 0.37 & 0.11 & 0.01 & 0.00 & 0.10 \\
SK & 0.41 & 0.13 & 0.17 & 0.61 & 0.05 & 0.03 & 0.01 & 0.21 \\
UK & 0.21 & 0.08 & 0.06 & 0.37 & 0.04 & 0.03 & 0.01 & 0.17 \\
\hline Total & 0.30 & 0.12 & 0.13 & 0.46 & 0.04 & 0.02 & 0.01 & 0.16 \\
\hline & & & & & & & &
\end{tabular}


Thirdly, the groups deprived in one dimension have substantively different profiles than those deprived in other dimensions in terms of their resources and needs. The results of which have been presented in Table S3, a multinomial logit model is run for each dimension to explore the profiles of people captured by each dimension. The dependent variables are categorized as not-identified, identified only in one dimension (e.g. basic) and identified in other dimensions (e.g. health, education and social). The reference category in each model is selected as "identified in other dimensions" to see how the profiles of deprived in each dimension are compared to the profiles of deprived in other dimensions. (The models are run for the whole EU sample with country fixed effects.) Same as the model applied in the main analysis, the explanatory variables are considered as the risk factors and represent either resources or needs (see Table 6 in the main text).

As shown in Table S3, for each dimension, the coefficients for many resource and need variables are statistically significant. In other words, the groups captured by one dimension significantly differ from the groups captured by other dimensions in terms of social class, education, economic well-being and various other need factors related to health, education and care. In addition, each dimension captures certain groups who are more likely to have needs in relevant dimensions. For example, the coefficients for variables that would proxy health care needs (e.g. disability or chronic health problem, or self-rated bad health in the household) are all significant and have higher effect sizes for health dimension than in others (except social dimension which shows the association between health and leisure and social activities). In other words, the households with higher health care needs are more likely to be captured by the health than in other dimensions. The households with education 
needs (e.g. having children in the household) are more likely to be deprived in education than in other dimensions.

Table S3: Comparing the profiles captured by each dimension using multinomial logit models- incidence rate ratios (IRR)

\begin{tabular}{|c|c|c|c|c|}
\hline & \multicolumn{4}{|c|}{ Base outcomes $=$ Other deprived } \\
\hline & $\begin{array}{l}\text { Model } 1 \\
\text { Basic }\end{array}$ & $\begin{array}{l}\text { Model } 2 \\
\text { Health }\end{array}$ & $\begin{array}{l}\text { Model } 3 \\
\text { Education }\end{array}$ & $\begin{array}{l}\text { Model } 4 \\
\text { Social }\end{array}$ \\
\hline \multicolumn{5}{|l|}{ Resources } \\
\hline \multicolumn{5}{|c|}{ HRP Social class (ref=Salariat) } \\
\hline Intermediate employee & 1.054 & 0.941 & $1.198^{* * *}$ & $1.223^{\star * *}$ \\
\hline Small self-emp. & 1.066 & $0.810^{* * *}$ & $1.225^{\star * *}$ & $1.429^{* \star *}$ \\
\hline Non-manual labor & 1.054 & 0.938 & $1.468^{* * *}$ & $1.297^{* * *}$ \\
\hline Manual labor & $1.217^{* * *}$ & $0.851^{* * *}$ & $1.650^{* * *}$ & $1.753^{\star * *}$ \\
\hline Excluded & 1.078 & $0.792^{\star \star *}$ & $1.184^{*}$ & $1.539^{\star \star *}$ \\
\hline \multicolumn{5}{|c|}{ HRP Education (ref=Third level) } \\
\hline Upper 2ndary & 0.977 & $0.847^{* * *}$ & $1.169^{\star * *}$ & $1.434^{\star \star *}$ \\
\hline Low2nd/Primary/Pre & 1.033 & $0.831^{* * *}$ & $1.365^{\star * *}$ & $1.924^{* * *}$ \\
\hline Unemployed in $\mathrm{HH}$ & $1.685^{\star \star \star}$ & $1.489^{\star \star \star}$ & $1.504^{\star \star *}$ & $1.990^{\star \star *}$ \\
\hline Tenant & $1.778^{\star * *}$ & $1.439^{* \star *}$ & $1.917^{\star \star \star}$ & 0.937 \\
\hline Income (log equiv.) & $0.633^{\star * *}$ & 0.976 & $0.622^{* * *}$ & $0.420^{\star \star \star}$ \\
\hline \multicolumn{5}{|l|}{ Needs } \\
\hline Disability in $\mathrm{HH}$ & $1.078^{\star *}$ & $1.160^{* * *}$ & $1.122^{* *}$ & $1.364^{* \star *}$ \\
\hline Chronic health pr. In $\mathrm{HH}$ & $1.076^{*}$ & $1.292^{* * *}$ & $0.917^{\star}$ & 0.989 \\
\hline Bad subj. health & $1.344^{\star * \star}$ & $1.303^{* * *}$ & $1.160^{\star \star *}$ & $1.743^{\star \star \star}$ \\
\hline Child aged $0-2$ in $\mathrm{HH}$ & $1.240^{\star * *}$ & $1.130^{* *}$ & $1.491^{* * *}$ & 1.034 \\
\hline Child aged 3-4 in HH & $1.120^{*}$ & 1.061 & $1.586^{\star \star \star *}$ & 0.974 \\
\hline Child aged 5-11 in $\mathrm{HH}$ & $1.245^{\star * *}$ & $1.218^{* * *}$ & $1.814^{* * *}$ & $1.184^{* * *}$ \\
\hline Child aged $12-15$ in $\mathrm{HH}$ & $1.081^{*}$ & $1.131^{* *}$ & $1.557^{* * *}$ & $1.182^{* * *}$ \\
\hline Single parent household & $1.297^{\star \star \star}$ & $1.158^{*}$ & 1.108 & $1.324^{\star \star \star}$ \\
\hline Extended family & 1.019 & 1.089 & $1.154^{* * *}$ & $1.404^{\star \star *}$ \\
\hline HRP divorced/separated & $1.229^{* * *}$ & $1.197^{* * *}$ & $1.316^{* * *}$ & $1.344^{* * *}$ \\
\hline HRP Female & $1.173^{* * *}$ & 0.998 & 1.039 & $1.202^{* \star *}$ \\
\hline
\end{tabular}

These findings show the value of including each dimension and evaluating them separately to cover different experiences of poverty. 
S2. A consistent poverty measure using the unadjusted proposed deprivation measure - a comparison to the consistent poverty measure of Whelan et al. (2013)

In this section, a consistent poverty measure is constructed combining the proposed multidimensional deprivation measure with a relative income poverty measure $(60 \%$ of median) and compared to the measure proposed by Maitre et al. (2013) (MWN hereafter) in their performance for identifying the people in poverty. For doing this, first, the agreement (and disagreement) between each measure is examined; then, the profiles of groups captured by each measure are compared based on some outcome indicators such as having difficulties making ends meet, financial strain and social class (ESEC 5).

In Table S4, headcount rates for each measure are presented for all countries. The results show that i) in average in the $\mathrm{EU}$, the proposed measure identified $13 \%$ of the population while the MWN measure identifies $9 \%$ of the population, ii) the variance of the proposed compared to the Maitre measure is slightly higher ( 0.11 vs. 0.08$)$, iii) the agreement between the two measure is very high and the only difference between the two measure is the additional group captured by the proposed measure. Following that, the question is whether this additional group improves the performance of a deprivation measure in identifying the people in poverty.

As shown in Table S5, among this additionally identified group, 78\% report having difficulties making ends meet compared to the EU average of $56 \% ; 48 \%$ report significant financial strain (2+ from the five item financial strain index) compared to the EU average of $33 \%$; more than $50 \%$ of the household heads (household reference person) is either working class or never worked compared to the EU average of $40 \%$; and only $12 \%$ of the household heads are in salariat class 
compared to the EU average of $30 \%$. Therefore, the proposed consistent poverty measure captures an additional group compared to the WMN measure; and this group is predominantly working class or never worked, and more likely to report difficulties making ends meet and financial strain.

Table S4: Poverty rates and mismatch between the proposed and the MWN measure across EU countries

\begin{tabular}{cccccc}
\hline Country & $\begin{array}{c}\text { Consistent } \\
\text { Deprived }\end{array}$ & $\begin{array}{c}\text { Consistent } \\
\text { WMN }\end{array}$ & Agreement & $\begin{array}{c}\text { Only } \\
\text { deprived }\end{array}$ & $\begin{array}{c}\text { Only } \\
\text { MWN }\end{array}$ \\
\hline AT & 0.09 & 0.06 & 0.95 & 0.03 & 0 \\
BE & 0.11 & 0.07 & 0.95 & 0.04 & 0 \\
BG & 0.21 & 0.21 & 0.98 & 0.01 & 0 \\
CY & 0.12 & 0.07 & 0.94 & 0.05 & 0 \\
CZ & 0.07 & 0.05 & 0.97 & 0.02 & 0 \\
DE & 0.12 & 0.09 & 0.96 & 0.03 & 0 \\
DK & 0.05 & 0.02 & 0.93 & 0.03 & 0 \\
EE & 0.17 & 0.09 & 0.92 & 0.08 & 0 \\
EL & 0.18 & 0.13 & 0.94 & 0.05 & 0 \\
ES & 0.14 & 0.06 & 0.90 & 0.08 & 0 \\
FI & 0.07 & 0.03 & 0.94 & 0.04 & 0 \\
FR & 0.10 & 0.07 & 0.96 & 0.03 & 0 \\
HU & 0.12 & 0.10 & 0.98 & 0.02 & 0 \\
IE & 0.12 & 0.05 & 0.93 & 0.06 & 0 \\
IT & 0.15 & 0.08 & 0.91 & 0.07 & 0 \\
LT & 0.18 & 0.14 & 0.95 & 0.04 & 0 \\
LU & 0.10 & 0.04 & 0.94 & 0.05 & 0 \\
LV & 0.24 & 0.20 & 0.95 & 0.05 & 0 \\
NL & 0.06 & 0.02 & 0.94 & 0.03 & 0 \\
PL & 0.16 & 0.11 & 0.94 & 0.05 & 0 \\
PT & 0.16 & 0.13 & 0.92 & 0.03 & 0 \\
RO & 0.22 & 0.20 & 0.97 & 0.02 & 0 \\
SI & 0.09 & 0.05 & 0.95 & 0.04 & 0 \\
SK & 0.10 & 0.07 & 0.97 & 0.03 & 0 \\
UK & 0.12 & 0.07 & 0.92 & 0.05 & 0 \\
\hline Total & 0.13 & 0.09 & 0.94 & 0.04 & 0 \\
\hline Variance & 0.11 & 0.08 & 0.06 & 0.04 & 0 \\
\hline & & & & &
\end{tabular}


Table S5: The profiles of the group identified only by the proposed measure

\begin{tabular}{lcc} 
Outcome indicators & codeprived=1 | WMN= & EU average \\
\hline $\begin{array}{l}\text { Having difficulties } \\
\text { making ends meet }\end{array}$ & $78 \%$ & $56 \%$ \\
Financial strain (2+) & $48 \%$ & $33 \%$ \\
ESEC (among HRP) & & \\
Salariat & $11.8 \%$ & $30 \%$ \\
Intermediate & $14.1 \%$ & $18.9 \%$ \\
Small self-employed & $21.6 \%$ & $11.2 \%$ \\
Non-manual labor & $11.5 \%$ & $8.8 \%$ \\
Manual labor & $31.8 \%$ & $27.7 \%$ \\
Never worked & $9.3 \%$ & $3.3 \%$ \\
\hline
\end{tabular}

Notes: The second column (codeprived=1 | WMN= 0 ) shows the ratios among the group identified additionally by the proposed measure.

Another issue to consider is the cross-country variation of the people identified only by the proposed measure. We see that the rate is around $1-2 \%$ for countries like Bulgaria, Romania and Hungary, while it is around 6-8\% for countries like Spain, Italy, Ireland and Estonia. This variation might be due to two different sources: i) as empirically shown by Beduk (2018b), the applied non-zero threshold in W\&M measure is more effective in distinguishing deprived and non-deprived for less affluent countries, and vice versa; therefore, a non-zero threshold is more likely to miss some people experiencing poverty in more affluent countries; ii) the difference might be higher in countries where health care and education is not publicly provided, thus in those countries, W\&M scale tend to miss people experience poverty related to missing dimensions. 